AEC RESEARCH AND DEVELOPMENT REPORT

\title{
PYROPHORICITY OF URANIUM IN REACTOR ENVIRONMENTS
}

\author{
G. E. ZIMA
}

JANUARY 22, 1960

IRRADIATION PROCESSING

HANFORD ATOMIC PRODUCTS OPERATION RICHLAND, WASHINGTON

\section{GENERAL GLG ECTRIC}




\section{LEGAL NOTICE}

This report was prepared as an account of Government sponsored work. Neither the United States, nor the Commission, nor any person acting on behalf of the Commission:

A. Makes any warranty or representation, expressed or implied, with respect to the accuracy, completeness, or usefulness of the information contained in this report, or that the use of any information, apparatus, method, or process disclosed in this report may not infringe privately owned rights; or

B. Assumes anty liabitities with respect to the use of, or for damages resulting from the use of any information, apparatus, method, or process disclosed in this report.

As used in the above, "person acting on behalf of the Commission" includes any employee or contractor of the Commission, or employee of such contractor, to the extent that such employee or contractor of the Commission, or employee of such contractor prepares, disseminates, or provides access to, any information pursuant to his employment or contract with the Commission, or his employment with such contractor. 
UNCLASSIFIED

HW -62442

UC-25, Metallurgy and Ceramics (TID-4500, 15th Ed.)

PYROPHORICITY OF URANIUM IN REACTOR ENVIRONMENTS

By

G. E. Zima

Process and Reactor Development Research and Engineering Operation

January 22, 1960

\section{HANFORD ATOMIC PRODUCTS OPERATION RICHLAND, WASHINGTON}

Work performed under Contract No. AT(45-1)-1350 between the Atomic Energy Commission and General Electric Company

Printed by/for the U. S. Atomic Energy Commission

Printed in USA. Price 80 cents. Available from the Office of Technical Services

Department of Commerce

Washington 25, D.C. 
TABLE OF CONTENTS

I. INTRODUCTION . . . . . . . . . . . . . . 3

II. SUMMARY . . . . . . . . . . . . . . . 3

III. GENERAL COMMENTS ON PYROPHORICITY. . . . . . 4

IV. REACTOR FIRE EXPERIENCE . . . . . . . . . . 19

V. SOME PHYSICAL AND CHEMICAL PROPERTIES OF URANIUM 26

A. Miscellaneous Physical Properties . . . . . . 26

B. Some Metallurgical Reactions . . . . . . . . 26

1. General . . . . . . . . . . . 26

2. Uranium-Aluminum $\quad . \quad$. $\quad . \quad$. . 31

3. Uranium-Silicon . . . $\quad$. . . . . . 34

4. Uranium-Zirconium . . . . . . . . . . 34

C. Chemical Reactions of Uranium . . . $\quad . \quad$. . $\quad . \quad 39$

1. General . . . . . . . . . . 39

2. Uranium-Water/Steam . . . $\quad . \quad$. $\quad 39$

3. Uranium-Hydrogen . . . $\quad$. . . 45

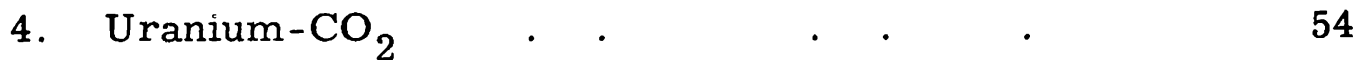

5. Uranium-Air . . $\quad$. $\quad . \quad$. 56

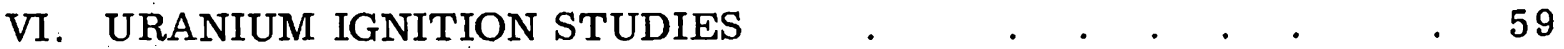

A. Influence of Specimen Factors . . . . . . $\quad . \quad \cdot \quad \cdot 61$

B. Influence of Environmental Factors . . . . 63

VII. CONCLUSION . . . $\quad$. . . $\quad$. $\quad .65$

ACKNOWLEDGEMENT • . . . . . . . . . 68

BIBLIOGRAPHY . 


\section{PYROPHORICITY OF URANIUM IN REACTOR ENVIRONMENTS}

\section{INTRODUCTION}

Under the stimulus of suitable physical and chemical conditions, the chemical reactivity of metallic uranium has been manifested in pyrophoric behavior and oxidation reactions of explosive violence. At least one compound of uranium, $\mathrm{UH}_{3}$, has demonstrated comparable reactivity and there is indication that some pyrophoric sensitization can be achieved by certain alloying elements. These characteristics are relevant to reactor systems where potential oxidizers function as coolants and moderators and where possible sensitizers--such as aluminum--work in close conjunction with uranium. With the trend to higher power levels and operating temperatures there are; apart from nuclear effects, four consequences of the accidental oxidation of uranium which command increasing respect in hazards analyses. These are, namely: fire and explosion hazard to operating personnel; fission product release to reactor and external environs; structural damage to core components; trigger action for major reactions between core materials--or their corrosion derivatives--and the ambient reactor atmosphere.

It is the intent of this report to review some of the current information relative to the pyrophoricity of uranium and to attempt to identify some aspects of this troublesome phenomenon which can support further investigation. The fortunately low incidence of metallic uranium fuel element fires, up to the present, does not suffice as an adequate base for extrapolation to future operations because of existing uncertainty with respect to both causative mechanisms and fire control techniques.

\section{SUMMARY}

Experience at Hanford reactors suggests three conditions which tend to reduce the fuel element fire hazard. These are, namely:

1. Minimizing of the in-core residence time of a fuel element with a cladding defect which permits uranium corrosion.

2. Employment of removal and discharge techniques which do not contribute to the deterioration of the fuel element. 
3. Minimizing of the time interval between discharge and entry into the retention basin.

Indifference to the first condition can aggravate the problem of fuel element removal by increasing the opportunity for buildup of: 1) $\mathrm{UH}_{3}$ and powdered uranium--which are believed to be the principal participants in fuel element fires; 2) corrosion products whose bulk can, eventually, seriously impede motion of the fuel element within the core. Indifference to the requirement for careful handling of defected fuel elements can provide, what is believed to be, the chief activation for fuel element fires. The residence time in the discharge area is important because during this interval there is considerable loss of control over fuel element cooling. The heat generated by radioactive decay would be expected to have maximum effect on the fuel element temperature during this interval. The consequence of a fuel element temperature excursion would depend, to some extent, on the structural and chemical condition of the element. For example, exposure of active material on the element, such as $\mathrm{UH}_{3}$ or powdered $U$, could markedly reduce the time to develop ignition of the massive uranium. Melting of the uranium would be a conceivable consequence of sustained residence in the discharge area--an effect which probably would not be strongly sensitive to the structural condition of the element at the time of discharge.

Helium, and to a lesser extent $\mathrm{CO}_{2}$, have demonstrated utility in inhibiting, and quenching, uranium fires. Supply systems for both of these gases are incorporated in present Hanford reactor plants. The fire control potential of these gases--used separately and in combination--should be explored.

A significant advance in present knowledge of pyrophoricity and closely related phenomena will require greater reliance on experimental analyses of metal-atmosphere systems in which an attempt is made to closely simulate the conditions of the working environment.

\section{GENERAL COMMENTS ON PYROPHORICITY}

A complete journal of instances of uranium pyrophoricity would probably encompass virtually every mechanical, physical, and chemical 
condition experienced by metallic uranium in processing and service environments. For the most part, the pyrophoric behavior has been observed under accident conditions and the recorded observations are necessarily superficial and often ambiguous. There is substantial literature on uranium pyrophoricity and no attempt at a detailed review will be made. The reports of $\operatorname{Smith}^{(1,2,3)}$ are particularly interesting for accounts and interpretative discussions of uranium fire incidents.

The pyrophoric potential of metal powders--particularly those metals ylelding strongly exothermic reactions with oxygen--is well known. Proceeding down the scale of specific area (surface area per unit mass) the incidence of pyrophoric behavior may be said, in general, to decrease with increase in size of the discrete reacting mass. The propensity of massive uranium to pyrophoric behavior is not, however, negligible. One-inch uranium rods, developed from billets by hot rolling, ignited before air cooling to room temperature could be effected and burning proceeded to complete oxidation of the metal. (1) Massive uranium pieces have ignited on storage shelves without apparent thermal, or mechanical, excitation. ${ }^{(1)}$ The instances of uranium fires involving machine turnings, compacted and loose scrap, and single pieces of various geometries, comprehend a variety of oxidizing atmospheres, a wide range of apparent pre-ignition temperatures and various kinds and degrees of mechanical and chemical excitation. This complex of conditions leading to pyrophoric behavior of uranium, coupled with the imperfect observations attending an accident, have made difficult any generalization concerning uranium pyrophoricity. In order to establish some frame of reference for subsequent comments on uranium, a brief discussion of pyrophoricity in general, with some data for other substances, is in order.

Smith ${ }^{(2)}$ suggests the generalization that any metal capable of exothermic reaction with oxygen should, in some physical state, be capable of spontaneous ignition. Considering the virtually limitless number of solid materials which could qualify as potentially pyrophoric under this criterion, a somewhat more restrictive statement would appear to be in order. It would be difficult, however to find a more detailed statement of pyrophoric conditions--qualifying as a generalization--which would substantially reduce 
the number of potentially pyrophoric, or explosive substances. The complex of physical and chemical factors contributing to the occurrence and importance of a pyrophoric incident defies a generalization which could be used for precise indexing of materials with respect to pyrophoric potential.

An energy producing, i. e. exothermic, reaction is a necessary, but not sufficient, condition for pyrophoric behavior. Physical and chemical couplings within the material comprised by the reacting system and between the material and the environment, determine the rates of energy production, the rates and modes of energy dissipation and, consequently, the history of the reaction after a sufficient activation has been received. Those conditions which tend to increase the rate of generation of reaction energy and temperature rise of the reacting system are obviously favorable to pyrophoric behavior. Among these may be mentioned: high energy release per unit volume of reacting material; large specific area (surface area per unit weight) of reacting material--with solid powder and finely dispersed liquid representing extremes in this respect and the gaseous phase perhaps the ultimate condition; an aggregation of active particles of high specific area, with a low gross specific area associated with the aggregate and a physical and chemical coupling within the aggregate which permits essentially simultaneous reaction of the particles; environmental conditions which inhibit heat transfer from the reacting system; derivatives from the primary oxidation reaction capable of exothermic reaction with the environment--with hydrogen perhaps the prime example here. These factors are cooperative and the extent of cooperation among these, and innumerable other favorable physical and chemical factors, determines the character of the reaction. The reaction violence may range from that of a slow, essentially isothermal, oxidation to an explosive release of reaction energy with detonation and shock wave generation the ultimate consequences.

A crude index of pyrophoric hazard, giving equal weight to physical and chemical factors might be the following:

$$
\text { Hazard Index }=\frac{M A_{p}^{*} \Delta H G}{\rho A_{S}^{*}} \quad \text { (energy density units) }
$$


where $\mathbf{M}$ is the mass of material capable of essentially simultaneous reaction--a capacity factor which, in conjunction with other factors, determines the magnitude of the energy release. $A_{p}^{*}$ is the specific area associated with the discrete reacting masses--a factor which has a strong influence on the course of the reaction rate with time, and hence the extent of the reaction; $\Delta H$ is the energy released per unit volume of reacting mass. Some adjustment of this factor could reflect the generation of explosive reaction products, such as hydrogen. $G$ is the moles of gas generated per unit volume of reacting mass--a factor which influences the pressure effects consequent from a reaction. $A_{S}^{*}$ is the gross specific area associated with the reacting masses--a factor which greatly influences the efficiency of environmental cooling factors and the extent of self shielding of the reaction heat.

Because of ignorance concerning actual, or potential, values of the $\mathrm{M}, \mathrm{A}_{\mathrm{p}}^{*}$ and $\mathrm{A}_{\mathrm{S}}^{*}$ terms pertaining to a given situation, this expression is of small practical value. This serious objection is, however, also applicable to more sophisticated expressions which purport to look closer into the phenomenon of pyrophoricity. The above expression is, perhaps, an acceptable identification of some of the more important factors influencing the character of a pyrophoric event.

Some physical property data, including specific heats of oxidation, for various materials are given in Table $I$. It is seen that, on a volume basis, the chemical energy releases from the oxidation of $U, A l$ and $\mathrm{Zr}$ are quite comparable.

The flame temperatures achieved by reaction of powdered metals with oxygen are among the highest which can be effected by chemical reaction. An appreciation for the order of magnitude involved can be gained from the following calculated adiabatic combustion temperatures for the $\mathrm{Al}-\mathrm{O}_{2}$ reaction $^{(4)}$ :

$\begin{array}{cc}\mathrm{P}(\mathrm{atm}) & \mathrm{T}\left({ }^{\circ} \mathrm{C}\right) \\ 1 & 3500 \\ 5 & 3800 \\ 10 & 4100\end{array}$




\section{TABLE I}

\section{SOME PHYSICAL PROPERTIES OF VARIOUS METALS}

\begin{tabular}{|c|c|c|c|c|c|c|c|}
\hline \multirow[b]{2}{*}{ Metal } & \multirow[b]{2}{*}{$\begin{array}{l}\text { Density } \\
\left(\mathrm{g} / \mathrm{cm}^{3}\right) \\
\end{array}$} & \multirow[b]{2}{*}{$\begin{array}{c}\text { M. } P . \\
\left({ }^{\circ} \mathrm{C}\right)\end{array}$} & \multirow[b]{2}{*}{$\begin{array}{c}\text { B. } P . \\
\left({ }^{\circ} \mathrm{C}\right) \\
\end{array}$} & \multirow[b]{2}{*}{$\underline{\text { Oxide }}$} & \multicolumn{2}{|c|}{ Heat of Combustion } & \multirow[b]{2}{*}{ Ref. } \\
\hline & & & & & $\begin{array}{l}-\Delta \mathrm{H}_{298} \\
(\mathrm{Kcal} / \mathrm{g}) \\
\end{array}$ & $\begin{array}{c}-\Delta \mathrm{H}_{298} \\
\left(\mathrm{Kcal} / \mathrm{cm}^{3}\right) \\
\end{array}$ & \\
\hline $\mathrm{Al}$ & 2.7 & 660 & 2330 & $\mathrm{Al}_{2} \mathrm{O}_{3}$ & 7.4 & 20.0 & 4 \\
\hline $\mathrm{Be}$ & 1.82 & 1280 & 2770 & $\mathrm{BeO}$ & 16. 2 & 30.0 & 4 \\
\hline $\mathrm{Fe}$ & 7.87 & 1539 & 2740 & $\mathrm{FeO}$ & 1.1 & 8.7 & 4 \\
\hline $\mathbf{M g}$ & 1.74 & 650 & 1130 & $\mathrm{MgO}$ & 5.9 & 10. 2 & 4 \\
\hline $\mathrm{Si}$ & 2. 33 & 1430 & 2600 & $\mathrm{SiO}_{2}$ & 7.3 & 17.0 & 4 \\
\hline Th & 11.5 & 1840 & $3000+$ & $\mathrm{ThO}_{2}$ & 1.26 & 14. 1 & 4 \\
\hline $\mathrm{Ti}$ & 4. 54 & 1820 & 3270 & $\mathrm{TiO}_{2}$ & 4.55 & 20.7 & 4 \\
\hline $\mathrm{U}$ & 19.04 & 1132 & 3818 & $\mathrm{UO}_{2}$ & 1.09 & 20.4 & 5 \\
\hline $\mathrm{U}$ & 19.04 & 1132 & 3818 & $\mathrm{U}_{3} \mathrm{O}_{8}$ & 1.02 & 22.4 & 5 \\
\hline $\mathrm{Zr}$ & 6.4 & 1852 & 3600 & $\mathrm{ZrO}_{2}$ & 2.84 & 18.1 & 4 \\
\hline & ---- & -- & -- & & --- & --- & \\
\hline $\mathrm{C}$ & 2.3 & & & $\mathrm{CO}_{2}$ & 7.83 & 18 & 4 \\
\hline $\mathrm{H}_{2}$ & & & & $\mathrm{H}_{2} \mathrm{O}$ & 29 & & 4 \\
\hline $\mathrm{C}_{2} \mathrm{H}_{2}$ & (acetylene) & & & & 11.5 & & 4 \\
\hline $\mathrm{UH}_{3}$ & 10.9 & & & $\mathrm{U}_{3} \mathrm{O}_{8}$ & 1. 12 & 12.2 & Calc. \\
\hline
\end{tabular}

The positive sensitivity to pressure is due to the fact that the temperatures corresponding to energy absorbing transitions (vaporization, dissociation, etc.) are raised as the pressure increases. Doyle ${ }^{(6)}$ has calculated the $\mathrm{Zr}-\mathrm{O}_{2}$ reaction temperature to be of the order of $4650 \mathrm{C}$ and there were indications that this order of magnitude was achieved in an experimental torch.

Some appreciation for the importance of the particle specific area $\left(A_{\mathrm{p}}^{*}\right)$ may be gained from the following simple analysis.

The instantaneous rate of temperature rise of reacting particle is,

$$
\frac{\mathrm{dT}}{\mathrm{dt}}=\dot{\mathrm{T}}=\frac{\mathrm{Q}_{\text {net }}}{\mathrm{Mc} \mathrm{c}_{\mathrm{p}}}
$$


where $Q_{\text {net }}=Q_{\text {reaction }}-Q_{\text {loss }}$

Now

$Q_{\text {net }}=$ rate of energy input from reaction - rate of energy loss to environment

$\mathbf{M}=$ mass of particle

$c_{p}=$ specific heat of material

$$
Q_{\text {reaction }}=\frac{\mathrm{k}_{\mathrm{n}} \alpha \Delta \mathrm{HA}}{\mathrm{nm}^{\mathrm{n}-1}}
$$

where $\alpha=$ fraction of reaction energy absorbed by particle

$\Delta \mathrm{H}=$ reaction energy per unit weight of reacting metal

$\mathrm{A} \quad=$ instantaneous metal surface area of reacting particle

and $k_{n}$ is a general oxidation rate constant corresponding to the oxidation rate expression,

$$
m^{n}=k_{n} t
$$

where $\mathrm{m}$ = weight of metal oxidized per unit area of specimen

$$
\mathrm{n} \quad=\text { rate index ( } 1 \text { for linear control, } 2 \text { for parabolic, etc.) }
$$

Neglecting the oxide thickness and the temperature change across the oxide:

$$
\mathrm{Q}_{\text {loss }}=\mathrm{hA}\left(\mathrm{T}-\mathrm{T}_{\mathrm{amb}}\right)
$$

where $T$ is an appropriate bulk temperature of the particle, $T_{a m b}$ is the effective temperature of the environment, $h$ is the over-all heat transmission coefficient. Substituting Equations 3 and 5 in 2:

$$
\mathrm{dT}_{\mathrm{n}} / \mathrm{dt}=\dot{\mathrm{T}}_{\mathrm{n}}=\frac{\mathrm{A}_{\mathrm{p}}^{*}}{\mathrm{c}_{\mathrm{p}}}\left[\frac{\alpha \Delta \mathrm{Hk}_{\mathrm{n}}^{1 / \mathrm{n}}}{\mathrm{nt}(\mathrm{n-1}) / \mathrm{n}}-\mathrm{h}\left(\mathrm{T}-\mathrm{T}_{\mathrm{amb}}\right)\right]
$$

or

$$
\dot{T}_{n}=\frac{A_{p}^{*}}{c_{p}}\left[\frac{C_{1} k_{n}^{1 / n}}{t^{(n-1) / n}}-h\left(T-T_{a m b}\right)\right]
$$

Under linear rate control $(n=1)$ Equation 6 a becomes,

$$
\dot{\mathrm{T}}_{1}=\frac{\mathrm{A}_{\mathrm{p}}^{*}}{\mathrm{c}_{\mathrm{p}}}\left[\mathrm{C}_{1} \mathrm{k}_{1}-\mathrm{h}\left(\mathrm{T}-\mathrm{T}_{\mathrm{amb}}\right)\right]
$$


In the above expressions $A_{p}^{*}$ is the particle specific area $(A / M)$ and the other terms have been defined previously. $\mathrm{C}_{1}=\alpha \Delta \mathrm{H} / \mathrm{n}$, assuming that these quantities can be represented by suitable, average values.

The second derivative with respect to time, $\ddot{T}$, is probably of equal, or greater significance. Retaining the generalized form of the oxidation law (Equation 4) and assuming a spherical particle, the expression for $\ddot{T}$, derived from Equation 6 is:

$\ddot{T}_{n}=\frac{A_{p}^{*}}{3 n c} p\left[\frac{C_{1} k_{n}^{2 / n}}{t^{2 n-2 / n}}-\frac{h k_{n}^{1 / n}}{t^{2 n-1) / n}}\right]+\frac{A_{p}^{*}}{c_{p}}\left[\frac{C_{1} k_{n}^{1 / n} Q \dot{T}}{n t^{(n-1) / n} R T^{2}}-\frac{C_{1} k_{n}^{1 / n}(n-1)}{n t^{(2 n-1) / n}}-n \dot{T}\right]$

where $Q$ is the activation energy for the oxidation reaction, which enters via the relation,

$$
\mathrm{k}_{\mathrm{n}}=\mathrm{k}_{\mathrm{n}}^{\mathrm{O}} \exp (-\mathrm{Q} / \mathrm{RT})
$$

Assuming a linear rate control, the above cumbersome expression simplifies somewhat to the following:

$$
\ddot{\mathrm{T}}_{1}=\frac{\mathrm{A}_{\mathrm{p}}^{*^{2}} \mathrm{k}_{1}}{3 \mathrm{c}_{\mathrm{p}}}\left[\mathrm{C}_{1} \mathrm{k}_{1}-\mathrm{h}\right]+\frac{\mathrm{A}_{\mathrm{p}}^{*} \dot{\mathrm{T}}}{\mathrm{c}_{\mathrm{p}}}\left[\frac{\mathrm{C}_{1} \mathrm{k}_{1} \mathrm{Q}}{\mathrm{RT}^{2}}-\mathrm{h}\right]
$$

Substitution of Equation $6 \mathrm{~b}$ for $\dot{\mathrm{T}}$ would give second degree involvement of the $A_{p}^{*}$ term in each part of Equation 8.

Inspection of the above expressions shows that the particle specific area $\left(A_{\mathrm{p}}^{*}\right)$ is a primary determinant of the temperature history of an oxidation event.

Some further emphasis of the importance of particle size to the temperature history is perhaps in order. Consider two particles of the same material, of instantaneous specific area $A_{\mathrm{p} 1}^{*}$ and $A_{\mathrm{p} 2}^{*}$, respectively. Now assume both are: (a) at the same temperature; (b) under the same linear oxidation control, i. e., $\mathrm{k}_{11} \equiv \mathrm{k}_{12}$; (c) comparable $\mathrm{T}_{\mathrm{amb}}$ and $\mathrm{h}$ values are associated with the two particles. At the instant these conditions obtain, from Equation $6 \mathrm{~b}$ :

$$
\frac{\ddot{\mathrm{T}}_{1}}{\mathrm{~T}_{2}}=\frac{\mathrm{A}_{\mathrm{p} 1}^{*}}{\mathrm{~A}_{\mathrm{p} 2}^{*}}
$$


and from Equation 8,

$$
\ddot{\mathrm{T}}_{1} / \ddot{\mathrm{T}}_{2}=\left(\mathrm{A}_{\mathrm{p} 1}^{*} / \mathrm{A}_{\mathrm{p} 2}^{*}\right)^{2}
$$

Now for spherical particles of radius $r, A_{p}^{*}=3 / r \rho$ therefore

$$
\dot{\mathrm{T}}_{1} / \dot{\mathrm{T}}_{2}=\mathrm{r}_{2} / \mathrm{r}_{1}
$$

and

$$
\ddot{\mathrm{T}}_{1} / \ddot{\mathrm{T}}_{2}=\left(\mathrm{r}_{2} / \mathrm{r}_{1}\right)^{2}
$$

These expressions at least suggest the strong influence of particle size on the temperature history of the particle. The previous expressions (Equations 6-8) have pointed up the adverse effect of conditions which reduce the heat dissipation to the surroundings, reflected by a reduction in $h$ and/or an increase in $\mathrm{T}_{\mathrm{amb}}$. While perhaps over-simplified, the above considerations are adequate for indicating the pyrophoric significance of a porous aggregate of small particles--probably the worst physical situation for pyrophoric material from a safety standpoint. It is a reasonably safe generalization that the most serious fire and explosion incidents with uranium and zirconium have involved aggregates of powder or small particles.

The character of a pyrophoric event appears to be strongly sensitive to the specific area(s) of the reacting masses. It follows, therefore, that the practical significance of any hazards analysis is largely dependent on the extent to which the analytical assumptions as to reactant dispersion reflect the dispersion potential of the working environment. Ignorance concerning this vital factor continues to present an important impediment to reactor hazard analyses concerned with reactions between core materials and reactor atmospheres.

There have been few basic studies with the objective of clarifying the phenomenon of pyrophoricity. Because of large scale handling of metal powder in industry, the bulk of the work has centered on metal, and related materials in powder form. The advent of nuclear reactors, incorporating large quantities of pyrophorically active materials, has provided a prime incentive for basic studies of pyrophoricity. Some of this work will be reviewed in a following section. 
While data on metal powder ignition is strongly sensitive to the experimental conditions--making extrapolation to a given working environment highly speculative--some of these data permit a rough gauging of absolute and relative pyrophoric hazards. Conway and Grosse ${ }^{(4)}$ have presented an excellent summary of the physical and chemical factors involved in the combustion of metal powders. One of their summaries of data on metal powder ignition, with data from several sources, is given in Table II. The various entries are explained at the bottom of the table. On the basis of ignition temperature, relative inflammability and $\dot{\mathrm{P}}_{\text {max }^{\prime}}$ these data identify $\mathrm{Zr}, \mathrm{Th}, \mathrm{Al}$ and $\mathrm{Mg}$ as particularly pyrophoric materials-corroborating practical experience with these metals. The data of Hartman are somewhat more relevant to the present report and, in conjunction with Table II, permit some indexing of the pyrophoricity of uranium relative to other metals. Some of Hartman's data, indicating the sensitivity of the ignition temperature to the ambient atmosphere, are given in Table III. Data were obtained for powder in cloud dispersions and in loosely packed layers. The cloud ignition tests consisted of blowing about one gram of powder into a vertical, electrically neated, muffle. The lowest muffle temperature at which flame could be observed issuing from the bottom of the muffle, was designed as the ignition temperature. In testing the powder layers, the test material was placed on an alumina $\left(\mathrm{Al}_{2} \mathrm{O}_{3}\right)$ disk at the center of the muffle. A slow stream of the test atmosphere was directed upward, over the specimen. The lowest temperature which gave some evidence of pyrophoric behavior, including accelerated powder temperature increase, was designated the ignition temperature.

Some pressure characteristics of the $\mathrm{U}$, and $\mathrm{UH}_{3}$ cloud ignitions are given in Figure 1 as a function of dust concentration. The particle size distributions for these powders are given at the bottom of the figure.

Hartman has also given oxygen tolerance levels for preventing dust cloud ignition by spark excitation, with $\mathrm{Ar}, \mathrm{CO}_{2}, \mathrm{~N}_{2}$, and $\mathrm{He}$ as the diluent gases. These data are given in Figure 2. The diluent gases, listed in order of decreasing effectiveness in suppressing ignition of $\mathrm{UH}_{3}$ are $\mathrm{He}, \mathrm{N}_{2}, \mathrm{Ar}$, and 


\section{TABLE II}

\section{A SUMMARY OF DATA ON METAL POWDER IGNITION IN AIR}

(From Reference 4)

\begin{tabular}{|c|c|c|c|c|c|c|c|c|}
\hline Metal & $\begin{array}{c}\text { Screen } \\
\text { Analysis } \\
\end{array}$ & $\frac{\mathrm{T}_{\text {ig }}}{\underline{\text { Cloud }}}$ & $\begin{array}{l}\left.{ }^{\circ} \mathrm{C}\right) \\
\text { Layer }\end{array}$ & Rel. Inflam. & $\begin{array}{l}\mathrm{P}_{\max } \\
\text { (psig) }\end{array}$ & $\begin{array}{c}\stackrel{\circ}{\mathrm{P}}_{\max } \\
(\mathrm{psi} / \mathrm{sec}) \\
\end{array}$ & $\begin{array}{c}\text { Min. Explos. } \\
\text { Conc. } \\
\text { (oz/ft } 3)^{\circ} \\
\end{array}$ & $\begin{array}{l}\text { Min. elect. } \\
\text { energy for } \\
\text { cloud ignition } \\
\text { (Millijoules) }\end{array}$ \\
\hline $\mathrm{Zr}$ & $100-44 \mu$ & R. T. & 210 & $90+$ & 50 & 5000 & 0.04 & 15 \\
\hline $\mathrm{Th}$ & $100-44$ & 270 & 280 & - & 80 & 6200 & 0.075 & 5 \\
\hline $\mathrm{Mg}$ & $87-53$ & 520 & 475 & $90+$ & 72 & 4760 & 0.025 & 80 \\
\hline $\mathrm{Al}$ & $80-53$ & 645 & 585 & $60+$ & 89 & 5700 & 0.035 & 50 \\
\hline $\mathrm{Ti}$ & $62-53$ & 480 & 460 & 55 & 52 & 1640 & 0.045 & - \\
\hline $\mathrm{Fe}$ & $100-53$ & 315 & 290 & 83 & 36 & 430 & 0.120 & 100 \\
\hline $\mathrm{Mr}$ & $100-7$ & 450 & - & 40 & 31 & 400 & 0.210 & 300 \\
\hline $\mathrm{Si}$ & $86-53$ & 775 & 950 & 0 & 62 & 1180 & 0.160 & $300-2000$ \\
\hline $\mathrm{Cu}$ & $98-44$ & 700 & - & 3 & - & - & - & 4000 \\
\hline
\end{tabular}

Screen Analysis: 100-44 denotes 100\% less than $44 \mu$ size

Rel. Inflammability: minimum \% of inert substance which will prevent ignition of dust cloud at $700 \mathrm{C}$

$P$ max : peak pressure developed in ignition apparatus

${ }_{\text {max }}$ : max. rate of pressure rise in ignition apparatus

Min. Explos. Conc.: minimum conc. of powder in air which will ignite and break paper diaphragm

Min. Elect. Energy: minimum spark energy which will cause ignition of dust cloud 


\section{TABLE III}

\section{IGNITION TEMPERATURES OF POWDERS}

IN VARIOUS ATMOSPHERES

(From Reference 7)

\begin{tabular}{|c|c|c|c|c|c|c|c|c|}
\hline \multirow[b]{2}{*}{ Powder } & \multicolumn{3}{|c|}{ Dust Clouds $\left({ }^{\circ} \mathrm{C}\right)$} & \multicolumn{3}{|c|}{ Dust Layers $\left({ }^{\circ} \mathrm{C}\right)$} & \multicolumn{2}{|c|}{$\begin{array}{l}\text { Energy for Ignition } \\
\text { (Millijoules) }\end{array}$} \\
\hline & $\underline{\underline{\text { Air }}}$ & $\mathrm{CO}_{2}$ & $\underline{\mathrm{N}}_{2}$ & $\underline{\underline{\text { Air }}}$ & $\underline{\mathrm{CO}}_{2}$ & $\underline{\mathrm{N}}_{2}$ & Cloud & Layer \\
\hline $\mathrm{U}$ & R. T. & 560 & none** & 100 & 350 & 410 & 45 & 4 \\
\hline $\mathrm{UH}_{3}$ & R. T. & 720 & none & R. T. & 360 & 210 & 5 & 32 \\
\hline $\mathrm{ZrH}_{2}$ & 430 & none & none & 340 & 650 & none & 100 & 64 \\
\hline $\mathrm{Zr}$ & R. T. & 650 & none & 190 & 620 & 790 & 12 & 240 \\
\hline $\mathrm{Ti}$ & 330 & none & none & 510 & 550 & 760 & 25 & 24 \\
\hline $\mathrm{TiH}_{2}$ & 440 & none & none & 500 & 710 & 750 & 60 & 1600 \\
\hline Th & 270 & 740 & none & 280 & 450 & 500 & 5 & 4 \\
\hline $\mathrm{ThH}_{2}$ & 260 & none & none & R. T. & 340 & 330 & 3 & 6.4 \\
\hline
\end{tabular}

$\mathrm{CO}_{2}$. It is interesting that this same listing obtains when the thermal conductivity at $0 \mathrm{C}^{(8)}$ is the criterion. Data reviewed by Coward and Jones ${ }^{(9)}$ indicate a somewhat different order of merit for these same gases when considering effectiveness in suppressing ignition of stoichiometric mixtures of hydrogen and oxygen, namely: $\mathrm{CO}_{2}, \mathrm{~N}_{2}, \mathrm{He}$, and Ar. This order is somewhat sensitive to the dimensions of the container, the given order applying to a tube of $2.2 \mathrm{~cm}$ diameter.

While these data on metal powders cannot be accorded strong quantitative significance because of their extreme sensitivity to environmental conditions, some of the qualitative information derived from these data is important to the subject at hand. First, finely divided $\mathrm{U}$ and $\mathrm{UH}_{3}$ can exhibit ignition temperatures of the order of room temperature, or below. Warf ${ }^{(10)}$ reports that spontaneous ignition of $\mathrm{UH}_{3}$ has occurred at dry ice temperatures $(-76 \mathrm{C})$. Second, both $\mathrm{CO}_{2}$ and $\mathrm{N}_{2}$ must be regarded as stimulative to the pyrophoricity of $\mathrm{U}$ and $\mathrm{UH}_{3}$, when temperatures order 


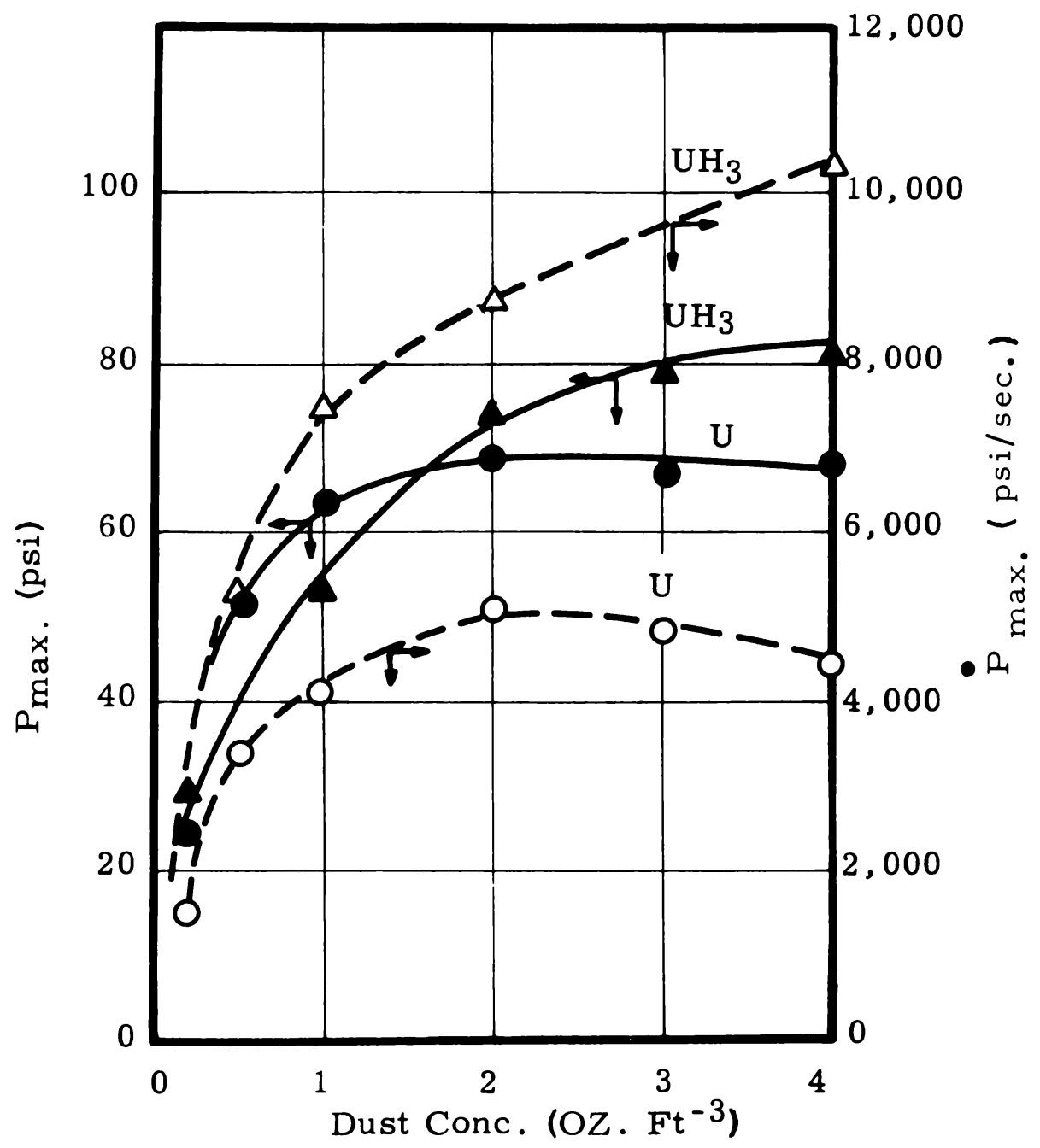

Test consisted of igniting given mixture in bomb of 1.2 liters capacity and monitoring pressure history with recording diaphragm manometer.

U powder size: 1-40 micron, av: 8-10 microns $\mathrm{UH}_{3}$ powder size: 1-12 micron, av: 3-5 microns

\section{FIGURE 1}

Some Pressure Characteristics of Powder Explosions (7) 


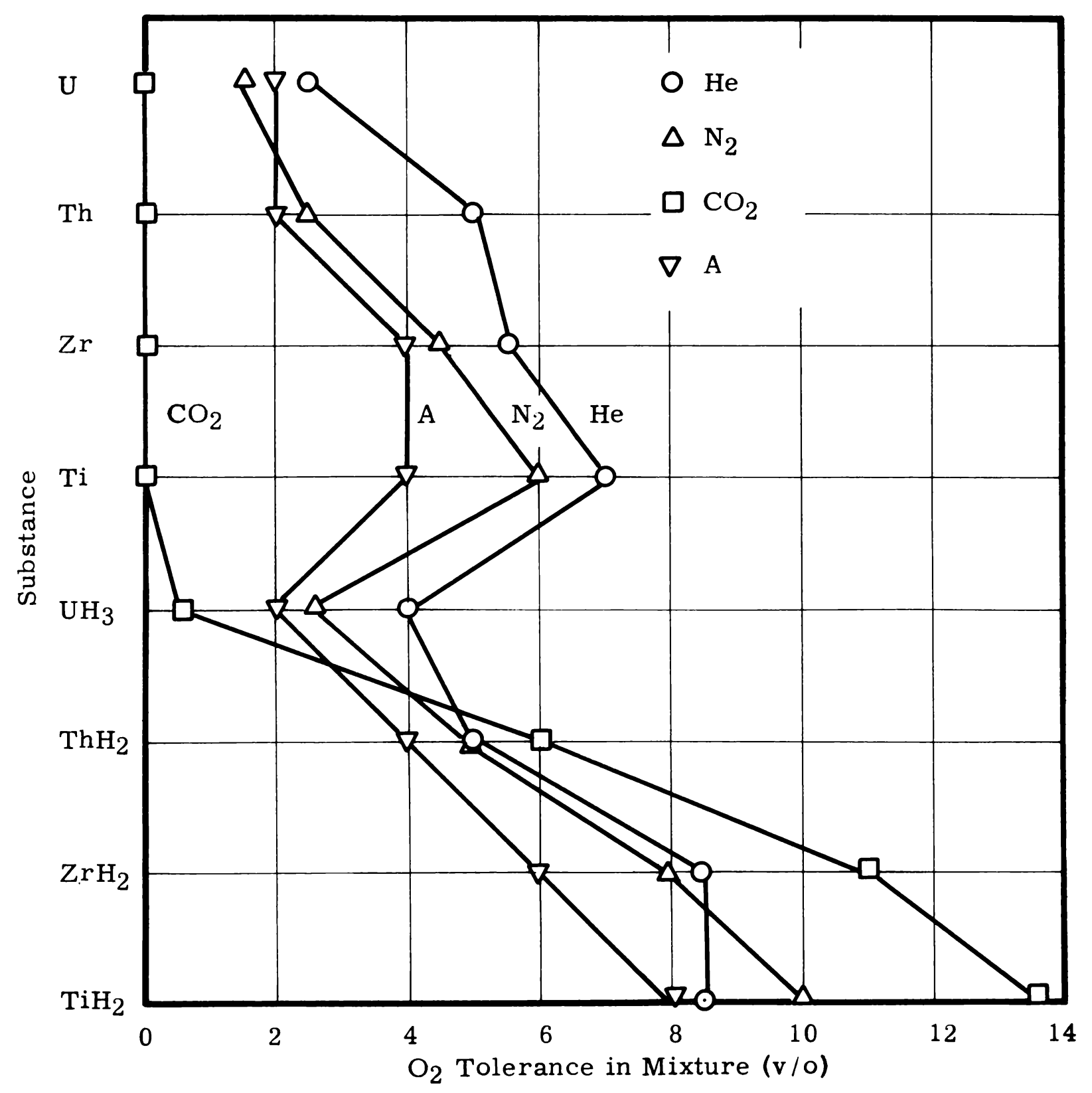

FIGURE 2

Oxygen Tolerance Levels to Prevent Spark Ignition of Dust Clouds (Ref. 7) 
of 2-400 $\mathrm{C}$ are involved. Some additional information on $\mathrm{CO}_{2}$ which, to some extent, refutes these conclusions is presented later. Helium appears to be the most effective suppressant of $\mathrm{U}_{\text {and }} \mathrm{UH}_{3}$ ignition. Third, the vol.:me specific energy release from the oxidation of $\mathrm{U}$ and $\mathrm{UH}_{3}$ is sufficient, under appropriate reactant and environmental conditions, to generate reactions of explosive violence.

There have been numerous studies of liquid metal-water reaction kinetics. A detailed review of this work is beyond the scope of this report. In general, these studies have further established the dominant role of specific area in determining the extent and rate of release of reaction energy. The effect of metal temperature on the water reaction is specific to each metal. As might be expected, different metals, under the same conditions of temperature and state of subdivision, will not show the same temperature response to a given oxidizing environment--water, or steam in this case. This is due primarily to differences in their oxidation characteristics and secondarily to differences in the heat transfer characteristics associated with the various oxide-metal complexes.

Some studies of the aluminum-water reaction by Long ${ }^{(11)}$ are illustrative of some of these points. The basic experiment consisted of discharging a quantity (10-50 lb) of molten aluminum into a container filled with water. Among the experimental variables pertinent to this discussion were the following: temperature of metal (1240-1650 F); diameter of metal stream entering bath (3/4 to 4 inches); drop distance to bath (3-30 inches); depth of water in bath (1/4-30 inches); dispersal of aluminum stream prior to entering the bath. Apparently two main conditions were requisite for a violent explosion, namely; enclosure of a quantity of liquid water by a compact mass of aluminum at the bottom of the container; an aluminum temperature sufficiently high to effect both a rapid, essentially explosive, vaporization of the water and a rapid oxidation of the metal particles created by the steam explosion. Conditions inimical to a high metal temperature were: a low pre-test metal temperature; too small a diameter for the meta stream entering the bath; too great a water depth; too great a drop height. Factors opposing the formation of a compact mass of metal at the bottom of the 
container were: preliminary dispersal of the stream by a grid; to shallow a bath depth. There was some question as to the extent of participation by various physical and chemical reactions (Al-water, $\mathrm{H}_{2}$-air). Under favorable circumstances, however, violent explosions qualifying as detonations were produced. These experiments with aluminum are significant to the present review in several respects. First, they probably demonstrate the importance of two factors previously mentioned in connection with the hazards index (Equation 1), namely: the amount of simultaneously reacting metal; the specific area of the reacting particles. Second, there was indication of the necessity for a metal temperature sufficiently high to yield rapid rates of energy exchange and release from the sequence of events attending the oxidation. This temperature which might be regarded as critical with respect to a rapid, or explosive, reaction would be sensitive to the physical and chemical factors previously discussed in connection with the temperature rise of a reacting particle. It would, therefore, be sensitive to the specific reaction conditions. (The tests with metal powders, previously cited, indicated that the oxidation characteristics of aluminum require that a relatively high temperature be attained before an explosive reaction is possible. Work at Aerojet ${ }^{(12)}$ corroborates this by showing that explosive reactivity with water requires temperatures considerably above the M. P. of aluminum.) Third, these tests demonstrated a mechanism for dispersal of molten metal which could conceivably have significance for a reactor environment. There is, as noted previously, a somewhat embarassing ignorance concerning possible dispersion mechanisms assignable to a given reactor system.

Uranium hydride has had extensive publicity as an important, perhaps pivotal, factor in the pyrophoric behavior of uranium. Certainly this attitude is supported by a number of physical and chemical characteristics of $\mathrm{UH}_{3}$. Under suitable pressure and temperature conditions, the hydride will generate finely divided uranium. As noted above, the hydride itself is highly pyrophoric. $\mathrm{UH}_{3}$ is formed under atmosphere and temperature conditions which are readily attainable in service environments. The hydride has been detected in spike penetration of the metal under corrosion conditions where uranium oxide was the principal product. These hydride spikes 
are potential triggers for a pyrophoric reaction in the event subsequent mechanical action creates active metal surface adjacent to the hydride. Waber $(13,14)$ has reviewed evidence that hydroxides, or hydrated oxides of uranium, may be important, possibly necessary, intermediates in the rapid oxidation of uranium in the presence of water or steam at certa in temperatures. Apparently little is known of the extent to which hydride and hydroxide actions are mutually exclusive, or cooperative, with respect to the oxidation processes of uranium in a hydrous environment. The capacity of free hydrogen, derived from the corrosion reaction, to initiate and augment a pyrophoric incident remains obscure. There is, however, increasing evidence that water, or hydrogen, is a virtual necessity at some stage in the history of a uranium fire, or explosion incident. Somewhat more detailed comments relating to uranium hydride are in a following section.

IV. REACTOR FIRE EXPERIENCE

The major hazard attending the combustion of irradiated uranium is the possibility of uncontrolled release of radioactive material. Loss of control could be effected by overburdening the containment facilities of the reactor or by bypassing containment facilities as a consequence of structural damage to the containment system. The burden imposed on radioactivity containment equipment by the cumbustion of even small quantities of uranium may be indicated by the fact that a fission product inventory of the order of 16 curies per gram of uranium can be developed by exposures of less than $1000 \mathrm{MWD} / \mathrm{T}$. Healy ${ }^{(15)}$ estimates that roughly 50 per cent of these fission products will be vaporized at temperatures the order of the melting point of uranium. Considering the possibilities of transferring the remaining, high boiling point, fission products as particulate matter, the radioactive contamination potential of a uranium fire is readily appreciated.

In considering uranium pyrophoricity in reactor environments, there are two general factors which must be added to the already complex situation obtaining for ex-reactor behavior. These are, namely: physical effects induced in metallic uranium by irradiation; chemical changes induced in the uranium-cladding complex by irradiation. Specific effects comprised by the first factor might be: cracking and porosity which greatly increase 
the potential, active, area associated with a given mass of uranium; residual stress which is a source of activation energy for an oxidation reaction; self heating from fission product decay; micro and macro defects which reduce the thermal conductance of the uranium and its ability to dissipate the fission product heat. The generation of fissures and porosity in metallic uranium by irradiation and the development of substantial stresses In a fuel element are known consequences of reactor service--the magnitude of which depend on service conditions and the fuel element fabrication history. Reductions of 10-15 per cent in the thermal conductivity have been reported ${ }^{(16)}$ for uranium after 0.02 per cent burnup. The second general factor might include fission and decay products which, depending on their disposition within the uranium, could impart local, or bulk, pyrophoric sensitization to the uranium. A number of fission and decay products, in suitable concentration, could possibly fulfill this function of increasing the pyrophoric potential of uranium. It is, therefore, not surprising to find considerable support for the belief that the pyrophoric potential of metallic uranium is markedly increased by reactor service. Fortunately, however, corroborating evidence is not impressive. The number of known fuel element fires in reactors, or their immediate environments, has been surprisingly low. Although the low fuel element failure frequency for Hanford reactors is a remarkably good testament to the excellence of fabrication and inspection techniques, it would have presented a significant operational problem had a fire and a release of fission products attended each defected element.

A list of the fire incidents--attributable to uranium or uranium compounds - - which have occurred in Hanford reactors is given in Table IV. The intensity and duration of these fires varied from essentially puff discharges of luminous particles to sustained fires which might have consumed the entire fuel element in the absence of quenching facilities. The sparse data and information available for each incident do not permit, to any extent, unambiguous identification of critical factors which were common to these incidents. In general, the temperature history of the fuel elements prior to the fire is indeterminant. Occurrence of the fires at various times following shutoff of the cooling water, plus the variation in fuel element 


\section{TABLE IV}

\section{HANFORD SLUG FIRE INFORMATION}

\begin{tabular}{|c|c|c|}
\hline Date & Tube/Reactor & Comments \\
\hline $11 / 1 / 55$ & $0961 / \mathrm{H}$ & $\begin{array}{l}\text { Recirculation loop facility. } \\
\text { Fire upon restoration of water to tube. } \\
\text { Puff fire inside tube(Ref. 17). }\end{array}$ \\
\hline $9 / 16 / 56$ & $1267 / \mathrm{C}$ & $\begin{array}{l}\text { Extended process tube broke under own } \\
\text { weight and exposed fuel element. } \\
\text { Element burned for about } 6 \text { min (Ref. 18). }\end{array}$ \\
\hline $9 / 27 / 57$ & $1965 / C$ & $\begin{array}{l}\text { Enriched (1. } 44 \%) \text { I \& } \mathrm{E} \text { fuel element } \\
\text { exposed after process tube broke under } \\
\text { under own weight. Element burned } \\
\text { about } 10 \text { min (Ref. 19). }\end{array}$ \\
\hline $4 / 29 / 59$ & $3091 / \mathrm{KW}$ & $\begin{array}{l}\text { Attempt to break extended section of } \\
\text { process tube left hanging tube segment } \\
\text { containing ruptured fuel element which } \\
\text { burned for } 3-5 \text { sec (Ref. 20). }\end{array}$ \\
\hline
\end{tabular}

exposure, suggest a substantial variation in the pre-ignition temperature history. When the defected fuel element effected partial blocking of the process tube, there is virtually no knowledge of the temperature abnormalities which might have contributed to the fire incident.

In three of the four incidents listed in Table IV, a fire, or pyrophoric display, was virtually simultaneous with a mechanical action which probably caused rapid exposure of sub-cladding material to the air. The breaking of a process tube at a section containing the defective fuel element is an example of such action. The circumstances attending the recirculation loop incident at $\mathrm{H}$ reactor also suggest that the fire resulted from sudden exposure of oxidizable material to air. In this case it is suspected that a protective layer of oxidation product was swept away by the air preceeding an advancing water slug. Sudden removal of a protective layer can be equivalent, in pyrophoric effect, to the more spectacular destruction of cladding noted above. The recirculation loop incident is probably evidence that this unwanted condition can be achieved by attempts at rapid cooling of a system which has experienced substantial oxidation. 
This indication that sudden exposure of oxidizable material is a critical factor in fuel fires is consistent with previous considerations of pyrophoricity in this report. Sudden exposure increases the amount of essentially simultaneously reacting material, which in turn increases the demand on environmental cooling factors if ignition is to be prevented.

Depending on the nature of the fuel element defect and the removal operations, the abnormalities of an element upon discharge from the core can range from relatively minute cladding perforations to gross loss of cladding. The fact that pyrophoric displays from these elements upon exposure to the air are rare occurrences suggests that protective oxidation products were developed during core residence. There are two implications here. Either the chemical-mechanical action on the fuel element while in the core is generally not sufficient to effect rapid exposure of active material to the process tube atmosphere, or the heat dissipation or oxidation characteristics of the process tube environment do not permit an ignition situation to develop. There have been occasional indications from radioactivity monitors that a puff discharge of radioactive material occurred while the fuel element was in core residence. From such exterior monitoring, it is impossible to judge whether this was a consequence of a fire action, or a removal of corrosion products by the process tube coolant. In the absence of action which effects rapid exposure of active material in the core, Hanford fuel fire experience indicates that the time between emergence from the process tube and fall into the retention basin is the critical period from the standpoint of fuel element fires. It will be indicated later that the criticality of this period is not as sensitive to fuel element temperature as might be expected.

Operations incidental to metallographic examination of irradiated uranium provide an excellent opportunity for the manifestation of irradiation induced pyrophoricity. Kittel ${ }^{(21)}$ reported on pyrophoric behavior displayed by irradiated specimens of natural uranium and various uranium alloys. Kittel's data are given in Table V. It was reported that combustion was sustained until the specimen was completely oxidized. Some dependence of ignition time on the specimen weight is indicated by these data. The 


\section{TABLE V}

\section{IGNITION DATA FOR IRRADIATED URANIUM}

(Reference 21)

\begin{tabular}{|c|c|c|c|c|c|c|c|}
\hline Composition & $\begin{array}{l}\text { Fabric and } \\
\text { H. T. } \\
\end{array}$ & $\frac{\text { Pre-irrad. }}{\underline{L}}$ & $\frac{\text { Size (In) }}{\underline{D}}$ & $\begin{array}{l}\text { Weight } \\
\text { (g) }\end{array}$ & $\begin{array}{l}\text { Exposure } \\
(\mathrm{MWD} / \mathrm{T})\end{array}$ & $\begin{array}{l}\text { Max. Irrad. } \\
\text { Temp. } \\
\left({ }^{\circ} \mathrm{C}\right) \\
\end{array}$ & $\begin{array}{l}\text { Approx. } \\
\text { Ignition Time* } \\
\text { (Min) } \\
\end{array}$ \\
\hline $\begin{array}{l}\mathrm{U}-0.52 \mathrm{w} / \circ \mathrm{Zr} \\
10 \% \text { enriched }\end{array}$ & $\begin{array}{l}\text { Swaged } 300 \mathrm{C}, \\
1 \mathrm{hr} 800 \mathrm{C} \text {; } \\
2 \mathrm{hr} 575 \mathrm{C}\end{array}$ & 0.750 & 0.125 & 2.8 & 14000 & 620 & 5 \\
\hline $\mathrm{U}, 10 \%$ enriched & As cast & 1.00 & 0.16 & 6.5 & 8400 & 790 & 10 \\
\hline $\mathrm{U}, 10 \%$ enriched & $\begin{array}{l}\text { Swaged } 300 \mathrm{C} \text {, } \\
20 \mathrm{~min} 725 \mathrm{C} \text {; } \\
2 \mathrm{hr} 575 \mathrm{C}\end{array}$ & 1.00 & 0.16 & 6.5 & 10000 & 720 & 15 \\
\hline Natural U & Powder Compact & 1.00 & 0.375 & 33.6 & 4500 & 770 & 40 \\
\hline $\mathrm{U}-10 \mathrm{w} / \circ \mathrm{Pu}$ & $\begin{array}{l}\text { Extruded } 500 \mathrm{C} \text {; } \\
2 \mathrm{~min} \text { at } 645 \mathrm{C} \text {; } \\
1 \mathrm{hr} 500 \mathrm{C}\end{array}$ & 0.750 & 0.120 & 2.8 & 3800 & 520 & 5 \\
\hline
\end{tabular}


temperature histories of these specimens, subsequent to irradiation, were not given. Photographs of typical specimens show that extensive roughening, and probably porosity, had developed as a result of the irradiation. Kittel noted, however, that spontaneous ignition was not characteristic of the bulk of the irradiated specimens subjected to the exposure levels given in Table V. The majority of the specimens exhibited normal, essentially isothermal, oxidation behavior. The factors which sensitized this material were not identified.

Unpublished work at ORNL (22) indicates that an exposure of the order of $500 \mathrm{MWD} / \mathrm{T}$ effects roughly a 50 per cent increase in the air oxidation rate of uranium, within the temperature range 800-1000 C. Lower exposure levels (unspecified) were said to have no influence on the oxidation rate. It was also reported that uranium containing small a mounts of aluminum exhibited an unusually rapid temperature rise upon exposure to air at temperaturesthe order of $400 \mathrm{C}$. Further information with regard to alloying effects will be discussed later. The significance of these oxidation data would be enhanced by information concerning the physical and chemical condition of the test material. A 50 per cent change in oxidation rate is well within the rather spectacular scatter band of reported oxidation data for unirradiated uranium and, hence, is not particularly illuminating.

Evidence of strong irradiation influence on uranium pyrophoricity has not been augmented by Hanford experience in handling irradiated uranium. A review of fire incidents with Hanford personnel handling both irradiated and unirradiated uranium has not revealed any particular bias with respect to the pyrophoric behavior of the two types of material. The exposure range presented by fuel elements whose abnormalities have occasioned destructive examination--roughly 100 to $2000 \mathrm{MWD} / \mathrm{T}$--should have been sufficient, however, to permit some identification of irradiation effects. In preparation for micro and macro examination, the fuel elements have been subjected to various mechanical operations, such as sawing, grinding, polishing, etc., which should have provided ample activation for a pyrophoric 
display. Fortunately, the Hanford fire experience has been very limited. There has been, however, a sufficient quantity of uranium handled, in various physical and chemical conditions, to present an impressive argument against the claim of strong irradiation influence on uranium pyrophoricity.

Available information on the $\mathrm{NRX}^{(23)}$ and Windscale ${ }^{(24)}$ reactor accidents--each involving melting of a substantial quantity of uranium-does not materially add to present knowledge of irradiation effects. The very restricted limits of observation attending these accidents permitted little opportunity to appraise the violence of the uranium oxidation. Post accident inspection of NRX core components suggested some correspondence between exposure level of the uranium and the extent of the oxidation. Hurst ${ }^{(23)}$ submitted that this difference in the oxidation response of the various fuel elements could be attributed to thermal conductivity decrease effected by the irradiation.

Inadvertent blocking of coolant to a process tube at the Hanford $\mathrm{K}$ reactor caused a local temperature excursion sufficient to melt a number of pounds of uranium. (25) Although there was surprisingly effective confinement and protection of the molten uranium by an Al-U diffusion product, there was some exposure of molten uranium to the ambient atmosphere. Extensive examination of the effected core components revealed remarkably little evidence of uranium oxidation--certainly no indication of a significant fire action. The oxidizing power of the atmosphere which might have been ambient to the uranium during the course of this accident cannot be determined, beyond the fact that both water and steam were involved at some stage. As noted above, temperatures in excess of the MP of uranium were attained by a substantial number of fuel elements. Several uranium castings were formed by ejection of molten uranium into graphite interstices following rupture of the process tube. During examination, one of these castings ( $1 / 4$ inch thick plates) ignited upon contact with tongs and burned completely. Kittel ${ }^{(21)}$ noted a similar occurrence. The exposure level of this material was far below the levels indicated in Table $V$ for Kittel's specimens. These castings were found to contain about $0.03 \mathrm{w} / \mathrm{o} \mathrm{Al}$. There was no identification of an active substance. 
Because there is still substantial ignorance concerning the physical and chemical factors affecting pyrophoricity, any denial of irradiation influence would be senseless. There is, as noted above, some conflict of evidence on this score. In the following, some facts relating to uranium corrosion and pyrophoricity will be reviewed. It will be indicated that the bulk of uranium fire experience to date can be explained without invoking a mysterious irradiation influence.

\section{SOME PHYSICAL AND CHEMICAL PROPERTIES OF URANIUM}

\section{A. Miscellaneous Physical Properties}

Some data on physical properties of uranium which are involved in considerations of heat dissipation and temperature response to a heat source are given in Figures 3, 4, 5, 6, and 7. In general, these data are sensitive to the chemical and metallurgical histories of the uranium. Most of these properties are affected, to some extent, by irradiation. Quantitative data on irradiation effects are not extensive and, in general, do not permit confident corrections to published data on unirradiated uranium. Because of the importance of the vapor phase to combustion processes, vapor pressure data for uranium, zirconium, and aluminum are given in Figure 8.

\section{B. Some Metallurgical Reactions}

1. General

Uranium must function in close conjunction with metals comprising the process tube, cladding and bond layers. The reactivity of uranium with these metals and the physical and chemical characteristics of the resulting alloys and compounds have an obvious importance to the subject of uranium pyrophoricity. Both the $\mathrm{NRX}^{(23)}$ and Hanford $\mathrm{K}$ reactor ${ }^{(25)}$ incidents provided demonstration of the powerful influence that metal-metal reaction can exert on the course of uranium oxidation in a reactor environment. Some indication of uranium reactivity with other metals is given in Tables VI and VII. Aluminum, silicon and zirconium are prominent co-workers with uranium in reactor service and somewhat more detailed consideration of the reactions of these metals with uranium is in order. 


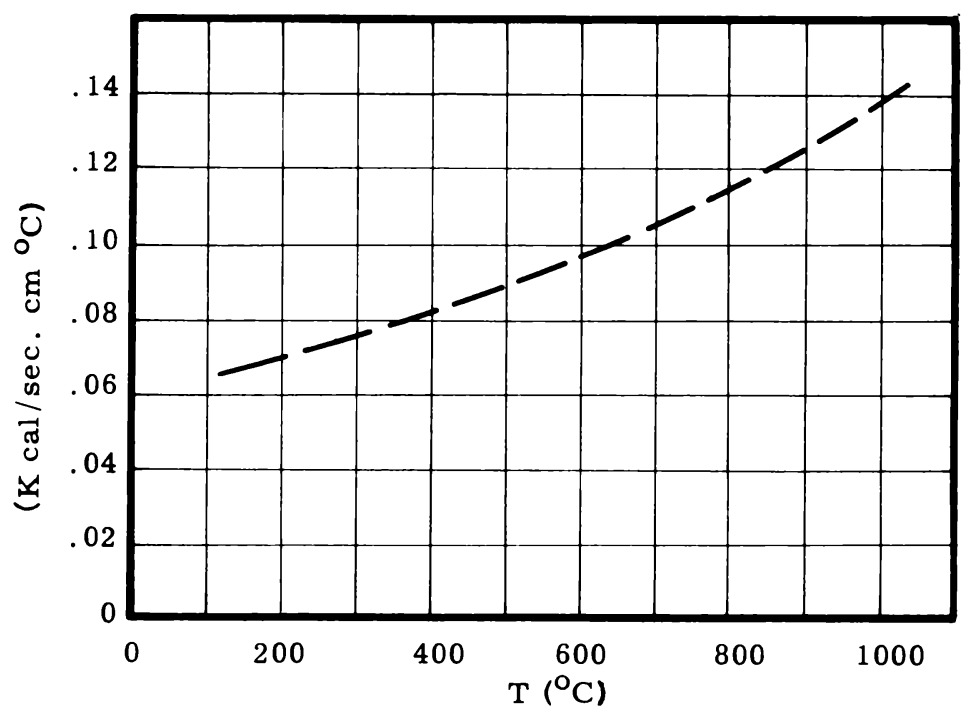

FIGURE 3

Thermal Conductivity of $U=F(T)$ (Ref. 16)

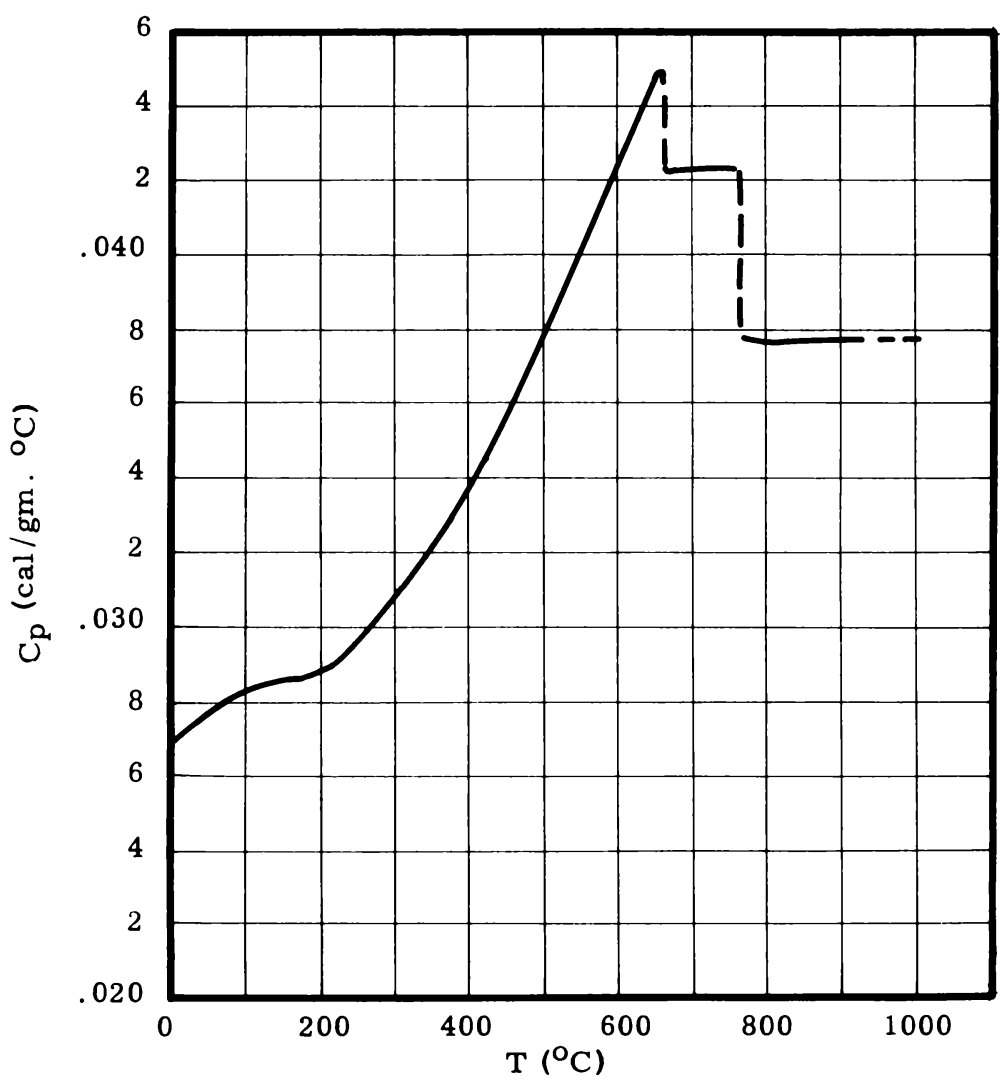

FIGURE 4

Specific Heat of $U=F(T)$ (Ref. 16) 


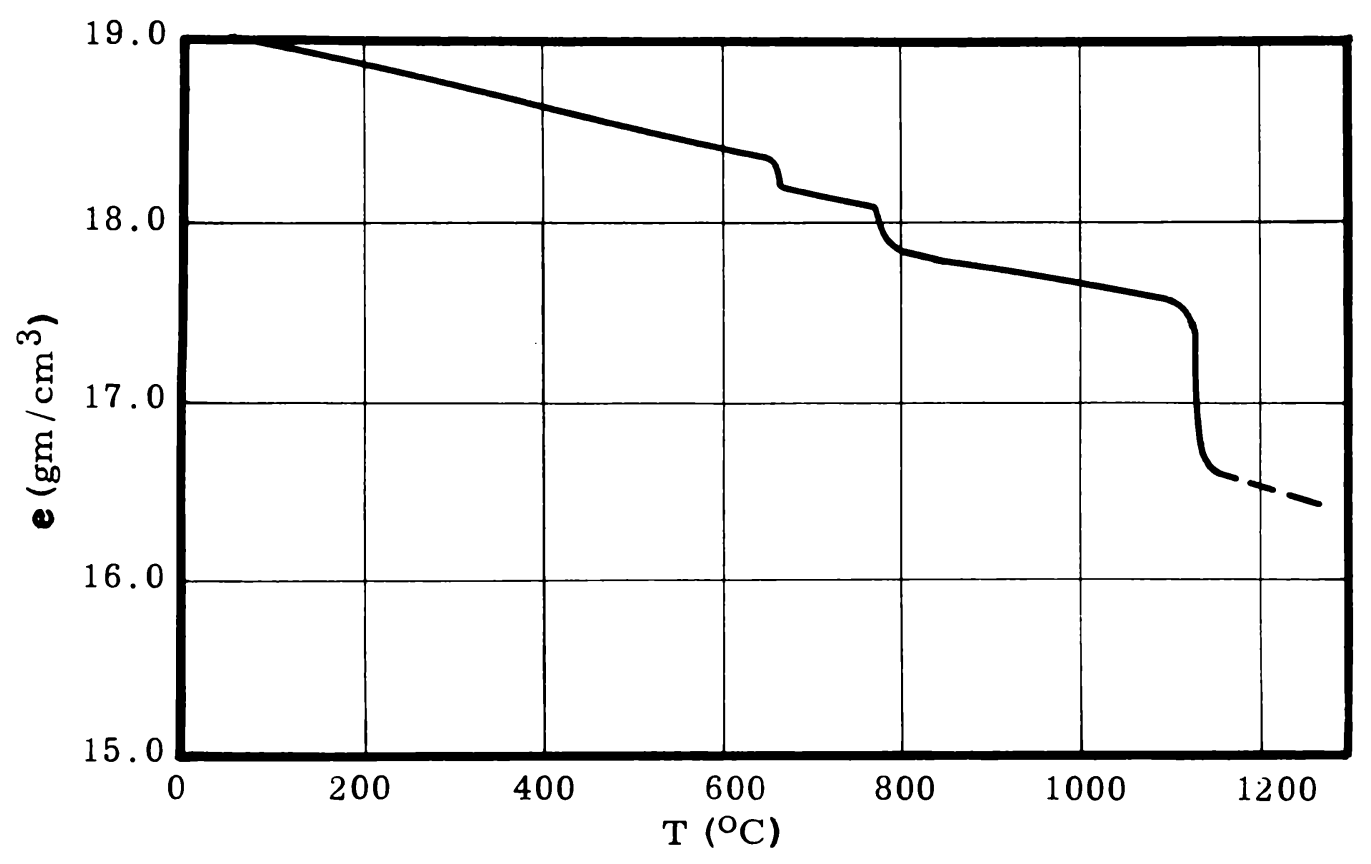

FIGURE 5

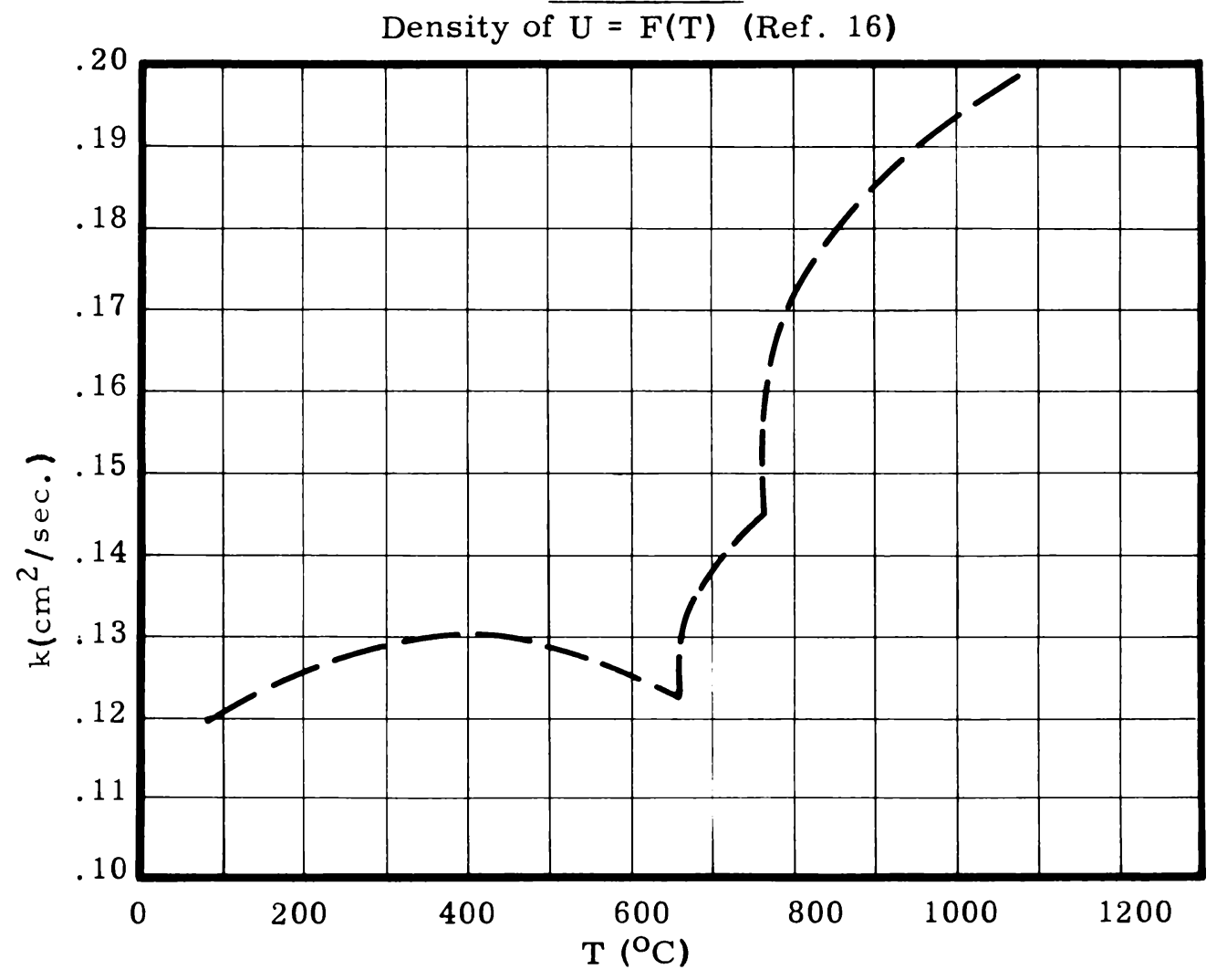

FIGURE 6

Thermal Diffusivity of $U=F(T)$ 


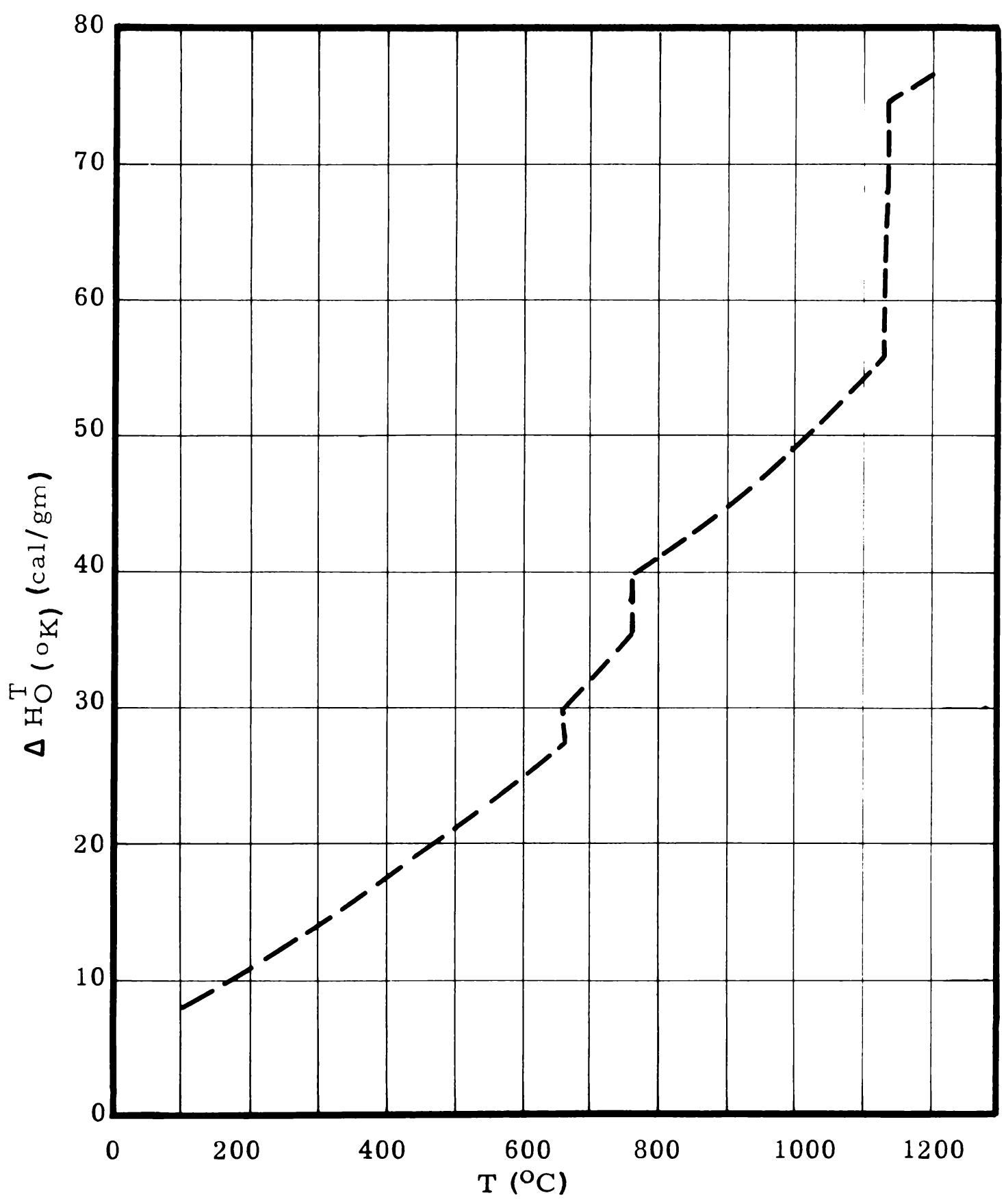

FIGURE 7

Heat Content of $U=F(T)$ (Ref. 16) 

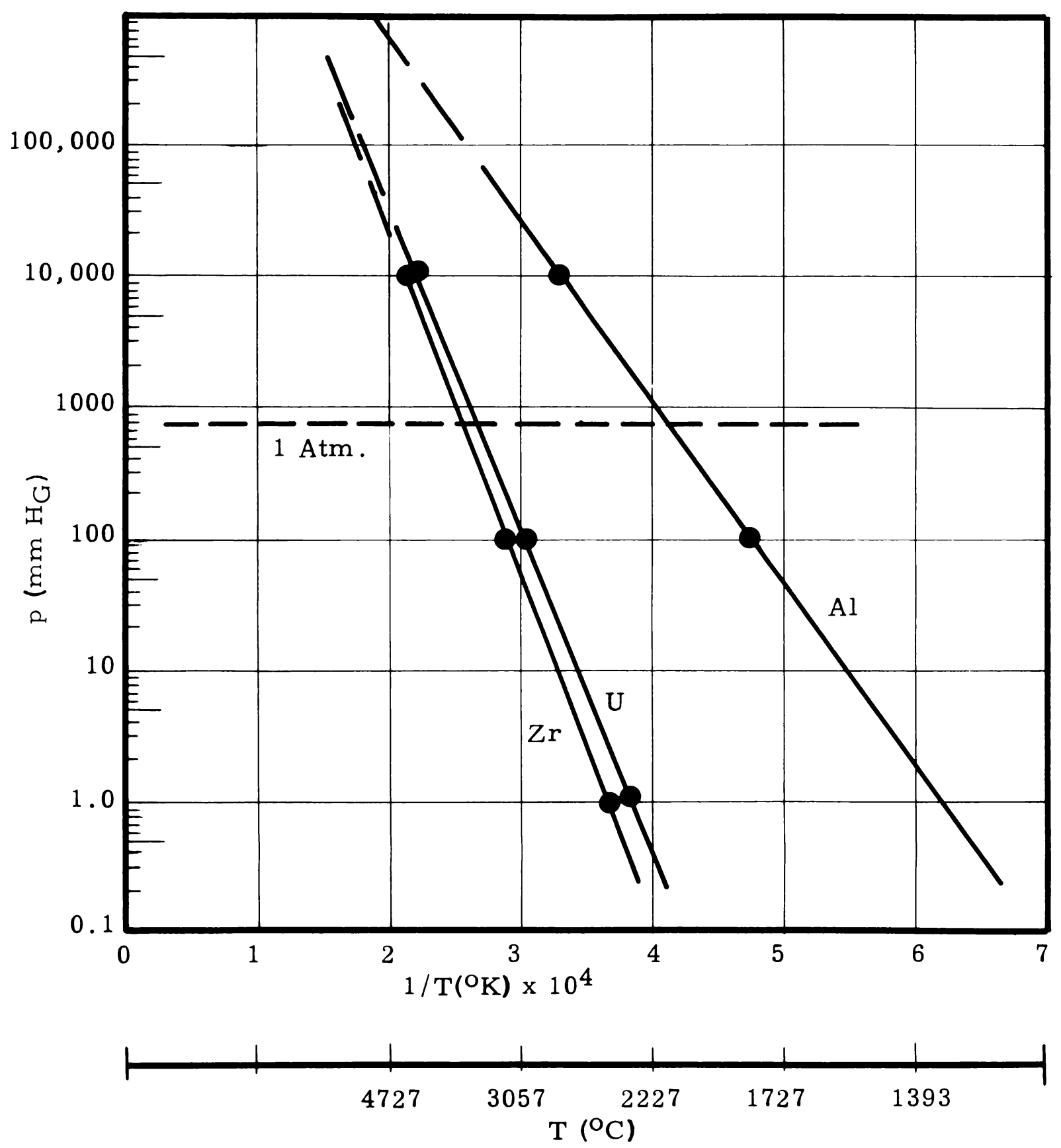

FIGURE 8

Vapor Pressures of $\mathrm{U}, \mathrm{Zr}$, and $\mathrm{Al}=\mathrm{F}(\mathrm{T})$

(Ref. 26) 
TABLE VI

\section{BEHAVIOR OF VARIOUS METALS WITH URANIUM}

(Reference 5)

\begin{tabular}{|c|c|c|}
\hline Class & Behavior & Metals $^{1}$ \\
\hline I & $\begin{array}{l}\text { Form intermetallic } \\
\text { compounds }\end{array}$ & $\begin{array}{ll}\mathrm{A}: \mathrm{Al}, \mathrm{Be}, \mathrm{Bi}, \mathrm{Co}, \mathrm{Cu}, \mathrm{Ga}, \mathrm{Au} \\
\mathrm{Fe}, \mathrm{Pb}, \mathrm{Mn}, \mathrm{Hg}, \mathrm{Ni}, \mathrm{Sn}\end{array}$ \\
\hline II & $\begin{array}{l}\text { Form solid solutions } \\
\text { but no intermetallic } \\
\text { compounds }\end{array}$ & $\begin{array}{l}\text { B: Ge, In, Ir, Pd, Pt, Tl, Zn } \\
\text { B: Mo, Ti, Zr, Nb }\end{array}$ \\
\hline III & $\begin{array}{l}\text { Form neither solid } \\
\text { solutions not inter- } \\
\text { metallic compounds }\end{array}$ & $\begin{array}{l}\text { A: Cr, Mg, Ag, Ta, Th, W, V } \\
\text { B: Ca, Ce, La, Nd, Pr, Na }\end{array}$ \\
\hline
\end{tabular}

TABLE VII

COMPATIEILITY OF VARIOUS METALS WITH URAINIUM

(Reference 27)

$\underline{\text { Metal }}$

Tungsten

Tantalum

Niobium

Zirconium

Titanium

Molybdenum

Tantalum coated nickel

Vanadium

Chromium

Nickel

Stainless steel

Nimonic ( $\mathrm{Ni}-\mathrm{Cr}-\mathrm{Fe}$ alloy)

Inconel ( $\mathrm{Ni}-\mathrm{Cr}-\mathrm{Fe}$ alloy)
Temp. at which 20-mil can is penetrated in $1 \mathrm{~min}$
1500

1460

1430

1380

1350

1280

1130

1130

1000

$850-950$ 


\section{Uranium-Aluminum}

The metallurgical reactions between $\mathrm{Al}$ and $\mathrm{U}$ are of particular interest because of two factors: there has been demonstration in the NRX ${ }^{23)}$ and $\mathrm{K}$ reactor ${ }^{(25)}$ accidents that extensive alloying, or intermetallic compound formation, can occur between Al cladding and $\mathrm{U}$ fuel in a loss-ofcoolant accident; there is good evidence that the resulting Al-U reaction product profoundly affects the extent to which both solid and molten uranium are influenced by the oxidizing atmosphere prevailing under the accident conditions. The U-Al phase diagram is given in Figure 9. This system exhibits very limited mutual solid solubility. At least three intermetallic compounds, namely: $\mathrm{UAl}_{2}, \mathrm{UAl}_{3}, \mathrm{UAl}_{4}$, can form in this system, with melting points of 1590,1350 , and $730 \mathrm{C}$, respectively. A eutectic, containing about $6 \mathrm{a} / \mathrm{o} \mathrm{Al}$ is reported at $1105 \mathrm{C}$. Diffusion tests with $\mathrm{U}-\mathrm{Al}$ couples have shown ${ }^{(16)}$ that $\mathrm{UAl}_{3}$ is the predominant phase generated by $\mathrm{U}-\mathrm{Al}$ diffusion at temperatures below the MP of Al. Until destroyed by physical, or chemical, action this phase could provide containment of molten $U$ up to temperatures the order of $1350 \mathrm{C}$--about $220 \mathrm{C}$ over the MP of $\mathrm{U}$. Analysis of slug material from the $\mathrm{K}$ reactor accident showed that $\mathrm{UAl}_{3}$ was the principal U-Al reaction product. One slug contained a region of finely dispersed $\mathrm{UAl}_{2}$ in a $\mathrm{U}$ matrix. The $\mathrm{UAl}_{3}$ was credited with containment of a substantial fraction of the molten $U$ generated by the accident.

Data given by Holden ${ }^{(16)}$ permit a rough estimate of the rate of formation of the $\mathrm{UAl}_{3}$ diffusion product as a function of time and temperature. If $\mathrm{X}$ is the thickness of the $\mathrm{UAl}_{3}$ layer, then the following rate equation has been found applicable:

$$
\mathrm{X}^{2}=\mathrm{A} \quad \mathrm{t} \exp (-\mathrm{Q} / \mathrm{RT})
$$

where $A$ is a pre-exponential term, $t$ is the diffusion time, $Q$ and $R$ are the usual pseudo activation energy and gas constant terms, respectively, arising from assumption of an Arrhenius type temperature dependence. Holden summarizes $A$ and $Q$ data from various sources for temperatures up to the MP of Al. $\mathrm{X}$ values corresponding to various temperatures and times were computed from these $A$ and $Q$ data. The roughly averaged results are 


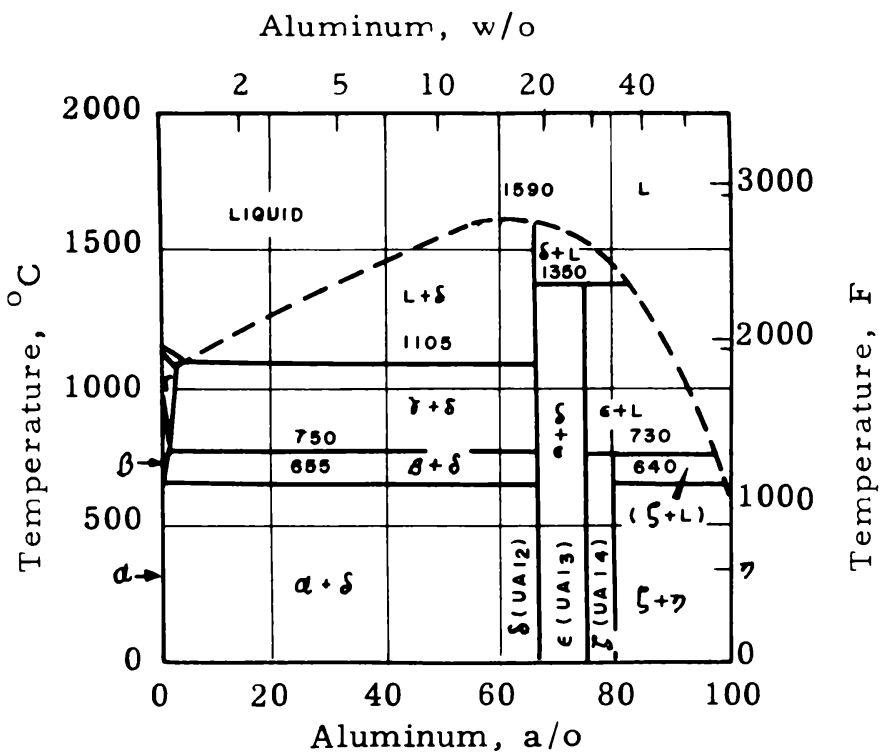

FIGURE 9

U-Al Phase Diagram (Ref. 16)

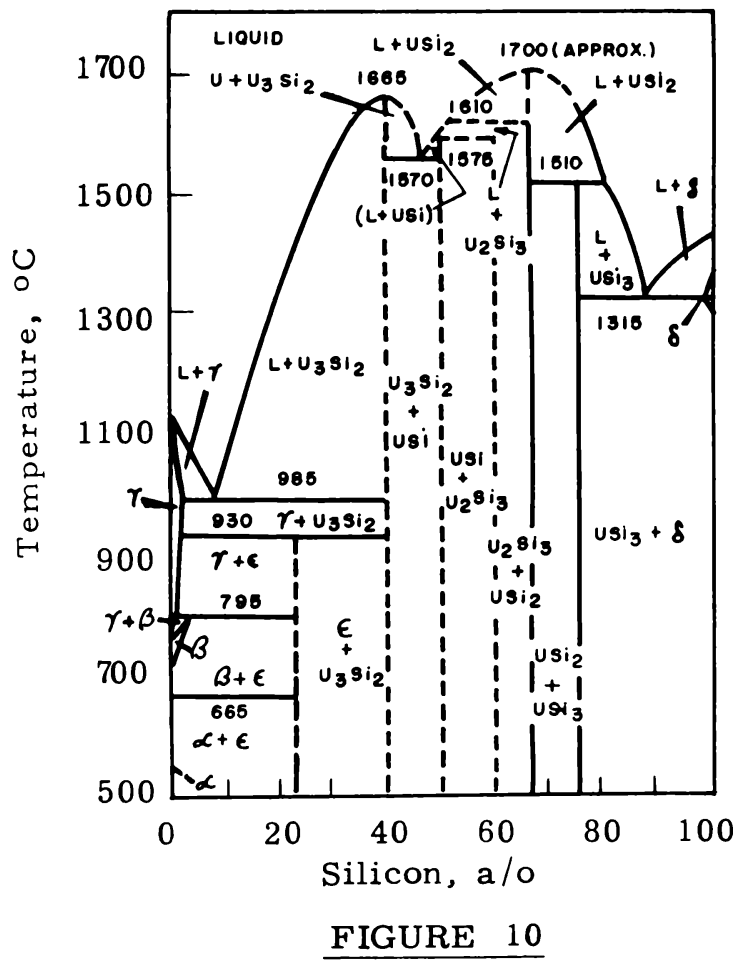

U-Si Phase Diagram (Ref. 16) 
summarized in Figure 12, where the $\mathrm{UAl}_{3}$ thickness $(\mathrm{X})$ is given as a function of $\mathrm{T}$ and $\mathrm{t}$. Above about $400 \mathrm{C}, \mathrm{UAl}_{3}$ formation reportedly shows a positive sensitivity to pressure. Quantitative information on this effect is sparce. Even with pressure corrections to the data of Figure 12, a sensible application of the corrections to a working environment would pose some difficulty.

There have been indications that small amounts of $\mathrm{Al}$ increase the oxiciation rate of irradiated $U$ and lower the ignition temperature of massive $U$. Some discussion of this is in a following section.

3. Uranium-Silicon

The use of Si as a thermal bond layer constituent in fuel slugs justifies a brief review of the U-Si system. The U-Si phase diagram is given in Figure 10. This system shows very limited solid solubilities. A number of intermetallic compounds are reported, namely: $\mathrm{USi}_{3}(1510), \mathrm{USi}_{2}(1610)$, $\mathrm{U}_{2} \mathrm{Si}_{3}$ (1610), USi (1575), $\mathrm{U}_{3} \mathrm{Si}_{2}$ (1665), and $\mathrm{U}_{3} \mathrm{Si}$ (930). The melting, or decomposition temperature $\left({ }^{\circ} \mathrm{C}\right)$, is given in parenthesis. A eutectic, containing about $8 \mathrm{a} / \mathrm{o} \mathrm{Si} \mathrm{melts} \mathrm{at} 985 \mathrm{C}$. Silicon in combination with $\mathrm{Al}$ ard U has demonstrated effectiveness in retarding water attack on $U^{(28)}$ No attempt at a review of the complex metallurgy and chemistry involved will be made. In an accident effecting gross melting of fuel elements and process tubes, the small quantity of silicon involved would not be expected to have a strong influence on the combustion characteristics of the metal assembly.

\section{Uranium-Zirconium}

The present, and proposed, use of $\mathrm{Zr}$ (principally as the Sn alloy, Zircaloy-2) for fuel element cladding and process tubes, forces attention to possible influences of this metal on the pyrophoric characteristics of uranium. As previously noted, $\mathrm{Zr}$, by itself, presents a fire and explosion hazard. This aspect of $\mathrm{Zr}$ has not been satisfactorily characterized with respect to reactor environments, and it demands further attention with the imminence of extensive use of $\mathrm{Zr}$ in large reactors. A brief discussion of this matter was included in a recent review of the properties of Zircaloy-2. 
HW-62 442

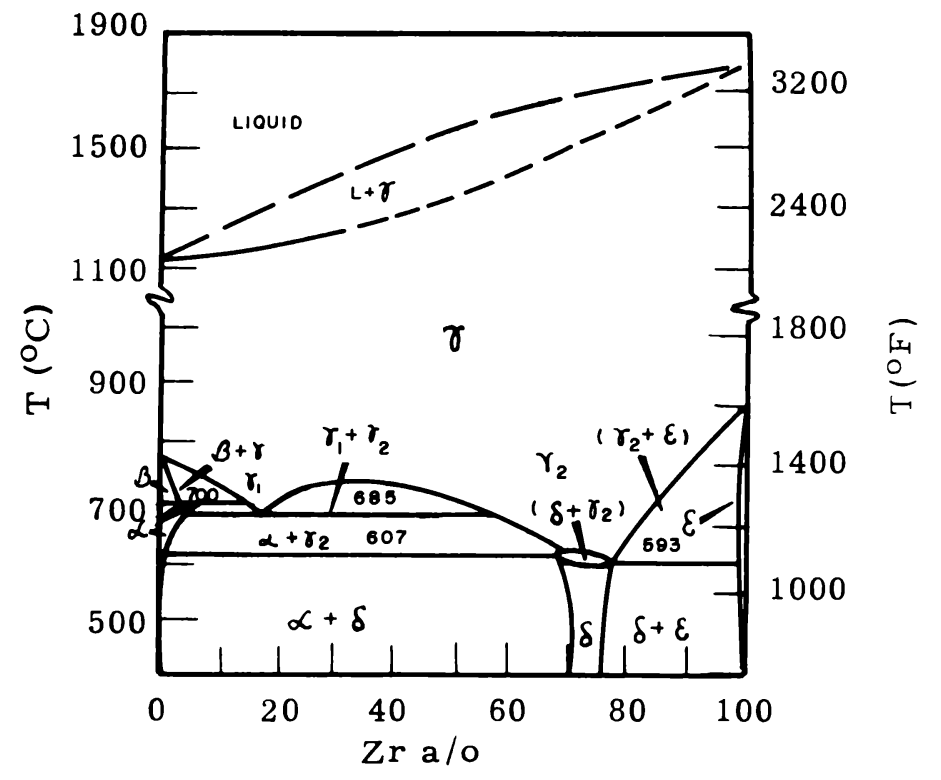

FIGURE 11

U-Zr Phase Diagram (Ref. 16)

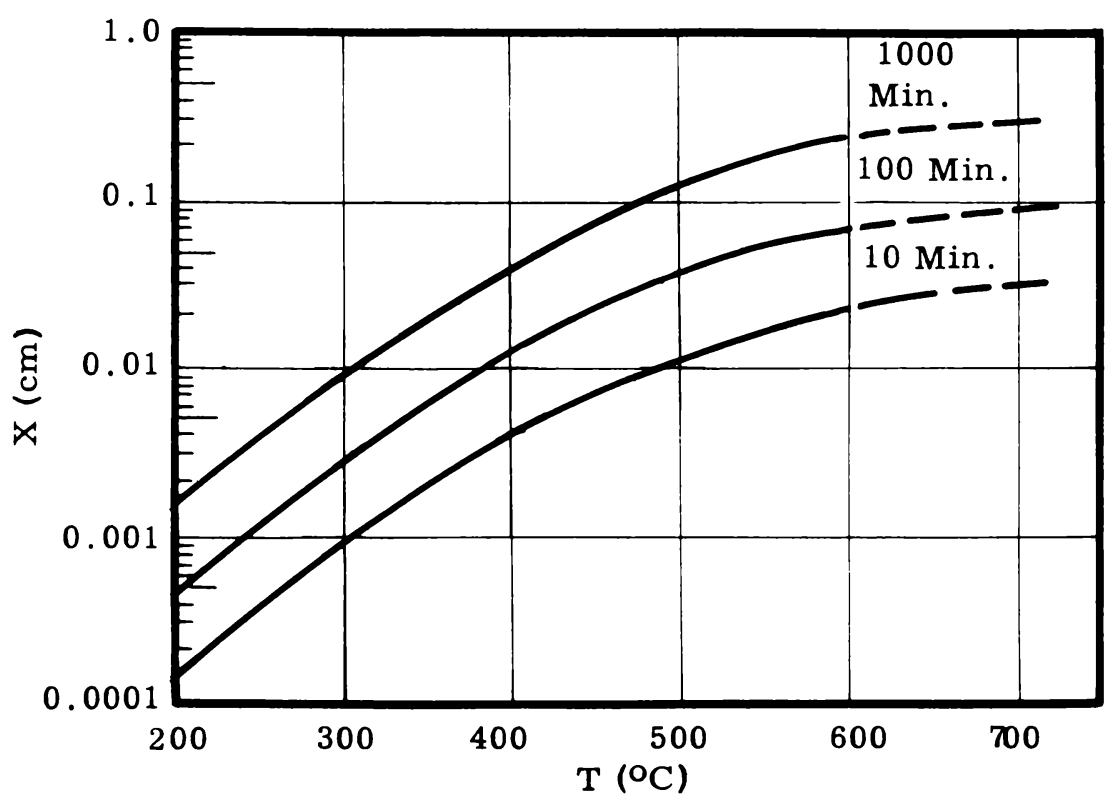

FIGURE 12

Penetration of $\mathrm{UAl}_{3}$ into $\mathrm{Al}$ Cladding $=\mathbf{F}(\mathrm{T})($ Ref. 16) 
The U-Zr phase diagram is given in Figure 11. This system exhibits unlimited mutual solubility below the liquidus and above roughly $870 \mathrm{C}$. The terminal solid solutions ranges are, as shown in Figure 11, very narrow. An intermetallic solid, delta, phase develops below about $600 \mathrm{C}$. This phase (occasionally called epsilon) spans a $\mathrm{Zr}$ range of about 65 to $75 \mathrm{a} / \mathrm{o}$. The violent explosions experienced during nitric acid etching of $\mathrm{U}-\mathrm{Zr}$ alloys have been attributed to this delta phase.

Gens ${ }^{(30)}$ has given a fairly detailed discussion of the factors involved in the explosive oxidation of U-Zr alloys. As indicated by Figure 11, this delta phase will form at temperatures below roughly $600 \mathrm{C}$ whenever the $\mathrm{U}$ or $\mathrm{Zr}$ content in the metal exceeds the solubility limits of the terminal solid solution involved. The alpha $U$ phase will tolerate only about $0.4 \mathrm{w} / \mathrm{o} \mathrm{Zr}$, while alpha $\mathrm{Zr}$ will contain a maximum of about $3.8 \mathrm{w} / \mathrm{o} \mathrm{U}$. The presence of finely dispersed delta phase within a matrix is believed to be a necessary, bur not sufficient, condition for an explosive reaction with etchants. The etchant must preferentially dissolve the matrix leaving a residue of delta particles of high specific area. With etchants of suitable oxidizing power, this aggregate of delta particles can oxidize explosively upon activation by stirring, etc. It has been found that U-Zr alloys containing less than about $30 \mathrm{w} / \mathrm{o} \mathrm{Zr}$ can generate a dispersion of delta phase in a $\mathrm{U}$ matrix which can satisfy the explosive conditions with $\mathrm{HNO}_{3}$. When $\mathrm{HF}$ is added to $\mathrm{HNO}_{3}$, in amounts sufficient to yield a $\mathrm{F} / \mathrm{Zr}$ mole ratio greater than about 4 , it prevents this explosive reaction by effecting rapid dissolution of the delta phase.

The significance of the U-Zr delta phase to the pyrophoricity of $U$ and U-Zr alloys is not clear. Obviously three factors are operative in the explosions with $\mathrm{HNO}_{3}$, namely: the high specific area of the reacting particles--which is consonant with previous sections of this report; a corrodant with a highly selective attack; a reactivity between the delta phase and the corrodant $\left(\mathrm{HNO}_{3}\right)$ sufficient to yield an explosion with aggregates of delta particles, under relatively mild activation. The occurrence of some delta phase would be an inevitable consequence of co-melting and solidification 
of $U$ and $\mathrm{Zr}$. Gens ${ }^{(30)}$ reports that temperatures in excess of $700 \mathrm{C}$ are required to develop delta phase in $\mathrm{Zr}-2$ clad uranium slugs. The delta phase has been observed in spike penetration of $\mathrm{Zr}$ boundaries, several mills away from the $\mathrm{Zr}-\mathrm{U}$ interface.

Using Equation 11, the growth of the delta phase within a U-Zr couple can be estimated from $A$ and $Q$ data obtained by Mash and Disselhorst.

The data are based on observations of phase boundaries at room temperature, after exposure at the indicated temperatures. $\mathrm{X}$ is the penetration of the $\mathrm{U}-\mathrm{Zr}$ diffusion zone (consisting either of pure delta, or a two phase mixture of delta in $\mathrm{Zr}$ ) into the $\mathrm{Zr}$ cladding. The thickness $\mathrm{X}$ of the diffusion zone is given as a function of exposure temperature and time in Figure 13 . The ranges of the diffusion temperatures and time used for the basic data of Figure 13 were 300-1050 C and 6-1812 hours, respectively.

According to the $\mathrm{U}-\mathrm{Zr}-\mathrm{O}$ terniary phase diagram ${ }^{(32)}$, existence of the delta phase is severely limited by dissolved oxygen (unstable for 0 concentrations greater than about $2 \mathrm{a} / \mathrm{o})$. While the capacity of $U$ for dissolved oxygen is low (about $0.003 \mathrm{w} / \mathrm{o}$ at the $\mathrm{MP}$ of $\mathrm{U}^{(33)}$ ), that of $\mathrm{Zr}$ is more than sufficient ${ }^{(34)}$ to strongly inhibit delta formation at temperatures where significant solid state diffusion occurs. Admitting the possibility of delta formation under accident, or abnormal operating conditions, the generation of an aggregate of delta particles requires that a substantial differential exist between the oxidation rates of the matrix metal and the delta phase. A pyrophoric display from the delta phase requires further: exposure of the delta particles to an oxidizing atmosphere; a reactivity with the atmosphere sufficient to cause ignition. Barnartt ${ }^{(35)}$ studied the oxidation characteristics of a $50 \mathrm{w} / \mathrm{O} \mathrm{U}-\mathrm{Zr}$ alloy in oxygen at one atmosphere pressure. This composition is within the delta range. It was reported that over the temperature range 200-500 C the alloy exhibited much lower oxidation rates than pure $U$ and somewhat higher rates than pure $\mathrm{Zr}$. This situation would favor the exposure of delta particles in a $U$ matrix but not in a $\mathrm{Zr}$ matrix--which is similar to the situation obtaining with $\mathrm{HNO}_{3}$ as the oxidizer. The fact the oxidation rate of the delta phase in $\mathrm{O}_{2}$ is substantially below that of $U$, suggests that no pyrophoric sensitization of massive $U$ would be expected 


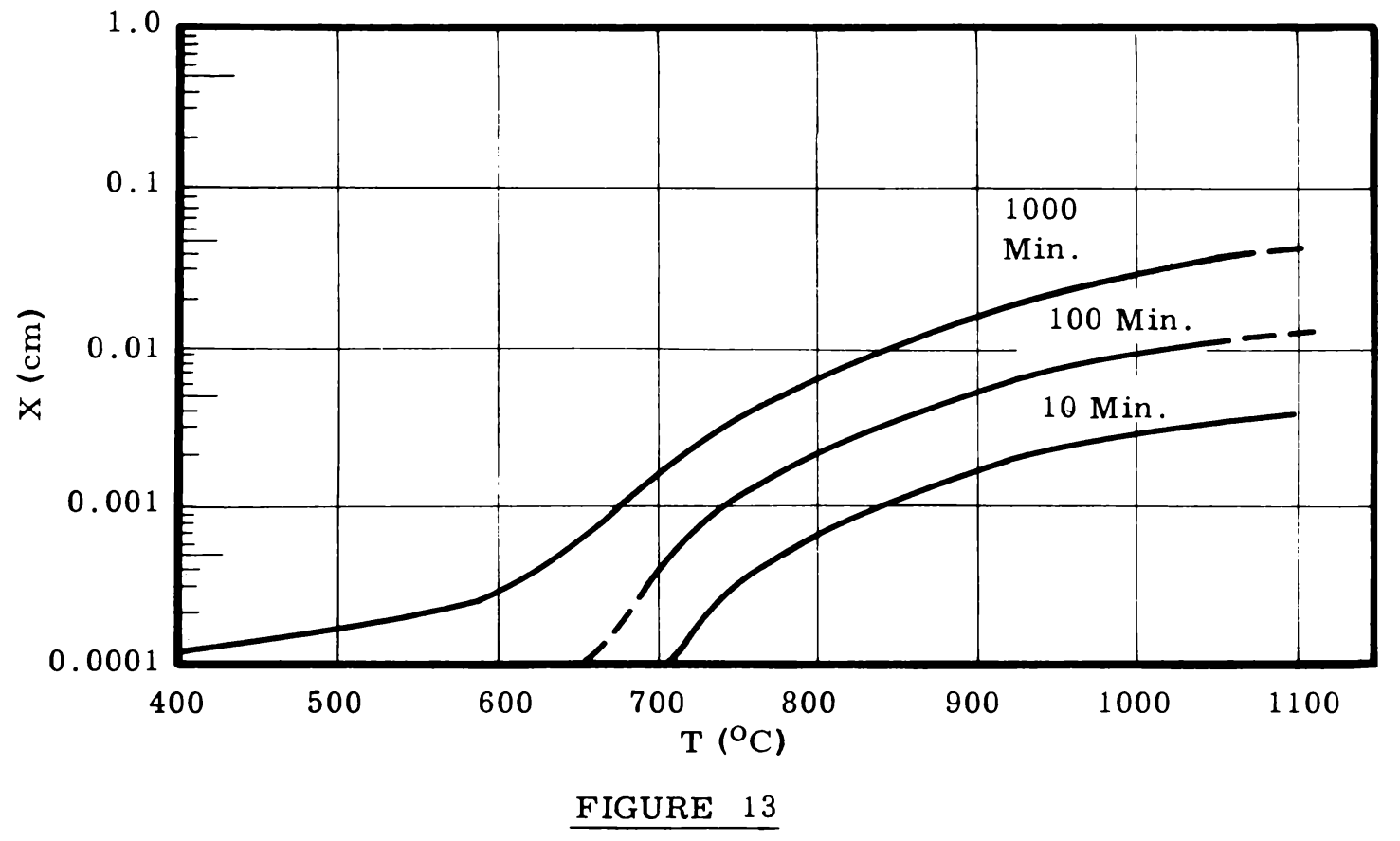

Penetration of $\mathrm{U}-\mathrm{Zr}$ Delta Phase into $\mathrm{Zr}$ Cladding = $F(T)$ (Ref. 31)

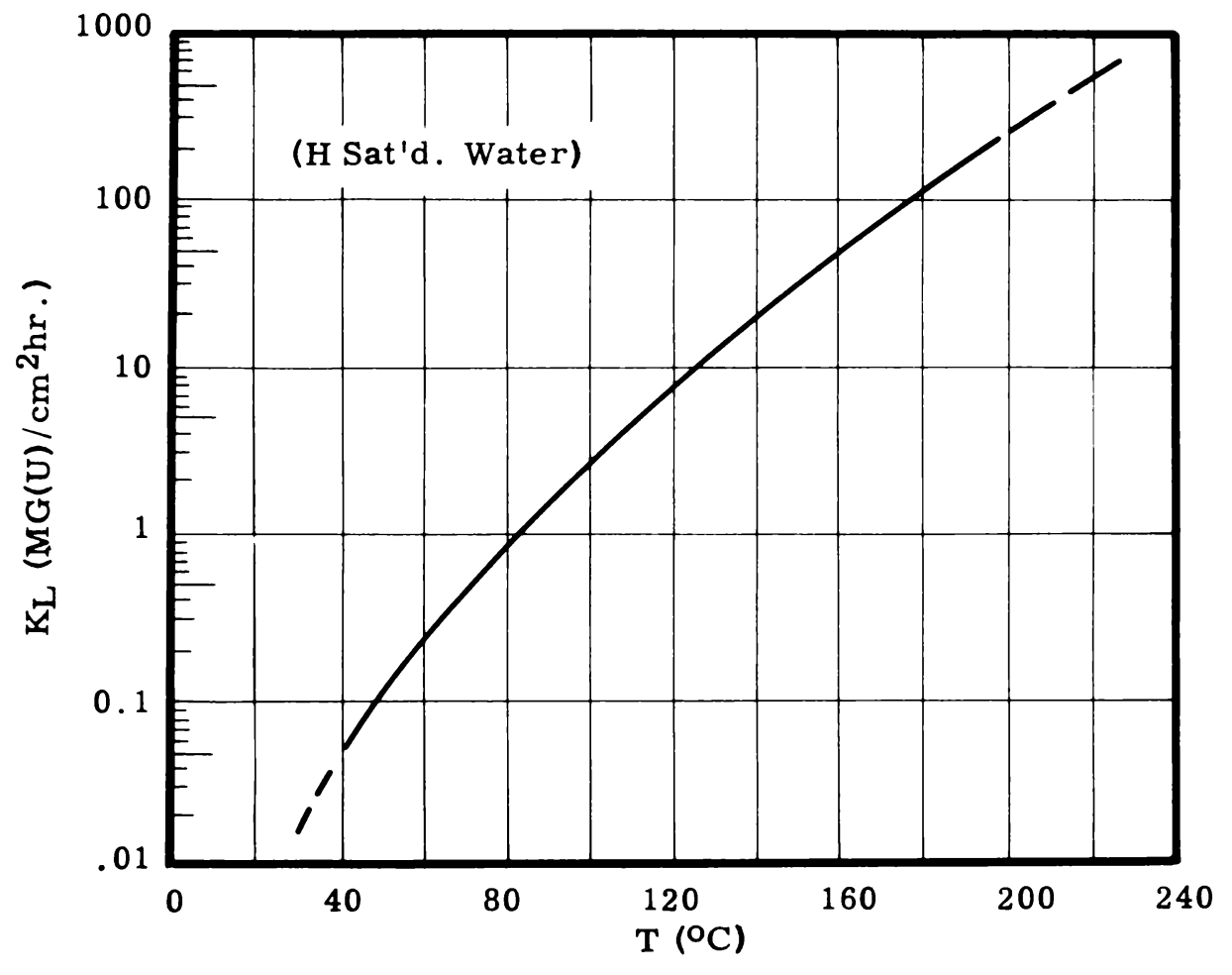

FIGURE 14

U Corrosion in Water $=F(T)($ Ref. 28) 
from delta inclusions. The pyrophoric behavior of finely divided delta phase in air would probably be comparable to either $\mathrm{U}$ or $\mathrm{Zr}$, although there is little information in this respect.

\section{Chemical Reactions of Uranium}

\section{General}

Miscellaneous reaction products of uranium are listed in Table VIII. Where available, heat of formation data are given, together with indications of the temperature at which a significant reaction rate occurs. The multiplicity of oxidation states of $U$ is reflected by the number of uranium compounds formed with a given reactant. In general, the existence limits of these compounds with respect to composition, temperature, and pressure, are not known extensively. Some of these compounds, such as $\mathrm{UH}_{3}$ and certain nitrides, are known to be pyrophoric. Undoubtedly a substantial number of the reaction products listed in Table VIII could fulfill the role of an igniter for uranium, under certain conditions.

Some considerations of the reactivity of $U$ with atmospheres having relevance to Hanford reactors are in the following sections.

\section{Uranium-Water/Steam}

Following the development of a cladding defect which permits contact of the $U$ with the process tube atmosphere, the reactions of $U$ with water and steam--probably in that order--control the development of protective oxide layers during subsequent cladding deterioration. This oxidation, as previously noted, is probably responsible for the inertness of defected fuel elements upon exposure to air at the time of discharge. Brugman and

Hoxeng ${ }^{(28)}$ have reviewed uranium-water corrosion data and their averaging of data from various sources is given in Figure 14, where the linear oxidation rate $\left(K_{1}\right)$ is given as a function of temperature.

These data are sensitive to sample and environmental factors, as well as the total exposure time and are, therefore, sufficient only for order of magnitude estimates of water corrosion damage to U. Uranium corrosion in water, at temperatures below about $212 \mathrm{~F}$, is strongly sensitive to the 
TABLE VIII

CHEMICAL REACTIONS OF METALLIC URANIUM

(Reference 5)

\begin{tabular}{|c|c|c|c|}
\hline Reactant & $\begin{array}{c}\text { Reaction Temp. } 1 \\
\left({ }^{\circ} \mathrm{C}\right)\end{array}$ & Product & $\begin{array}{c}{ }^{-\Delta_{\mathrm{H}^{\circ}} \text { formation }} \\
\text { (Kcal/mol product) }\end{array}$ \\
\hline $\mathrm{H}_{2}$ & 250 & $\mathrm{UH}_{3}$ & 30.4 \\
\hline $\mathrm{C}$ & $1800-2400$ & $\mathrm{UC}, \mathrm{U}_{2} \mathrm{C}_{3}, \mathrm{UC}_{2}$ & 28 (UC) \\
\hline $\mathrm{N}_{2}$ & 700 & $\mathrm{UN}, \mathrm{UN}_{2}$ & $80(\mathrm{UN})$ \\
\hline $\mathbf{P}$ & $1000 \mathrm{P}$ & $\mathrm{U}_{3} \mathrm{P}_{4}$ & \\
\hline $\mathrm{O}_{2}$ & $150-350$ & $\mathrm{UO}_{2}, \quad \mathrm{U}_{3} \mathrm{O}_{8}$ & $854\left(\mathrm{U}_{3} \mathrm{O}_{8}\right)$ \\
\hline$S$ & 500 & $\mathrm{US}_{2}$ & \\
\hline $\mathrm{F}_{2}$ & 250 & $\mathrm{UF}_{6}$ & 505 \\
\hline $\mathrm{Cl}_{2}$ & 500 & $\mathrm{UCl}_{4}, \mathrm{UCl}_{5}, \mathrm{UCl}_{6}$ & $251\left(\mathrm{UCl}_{4}\right)$ \\
\hline $\mathrm{Br}_{2}$ & 650 & $\mathrm{UBr}_{4}$ & 197 \\
\hline $\mathrm{I}_{2}$ & 350 & $\mathrm{UI}_{3}, \mathrm{UI}_{4}$ & $115\left(\mathrm{UI}_{3}\right)$ \\
\hline $\mathrm{H}_{2} \mathrm{O}$ & 100 & $\mathrm{UO}_{2}$ & 259 \\
\hline HF (gaseous) & $350 P$ & $\mathrm{UF}_{4}$ & 443 \\
\hline $\mathrm{HCl}$ (gaseous) & $300 P$ & $\mathrm{UCl}_{3}$ & 213 \\
\hline $\mathrm{NH}_{3}$ & 700 & $\mathrm{UN}_{1.75}$ & \\
\hline $\mathrm{H}_{2} \mathrm{~S}$ & $500 \mathrm{P}$ & $\mathrm{US}, \mathrm{U}_{2} \mathrm{~S}_{3}, \quad \mathrm{US}_{2}$ & \\
\hline NO & 400 & $\mathrm{U}_{3} \mathrm{O}_{8}$ & \\
\hline $\mathrm{N}_{2} \mathrm{O}_{4}$ & 25 & $\mathrm{UO}_{2}\left(\mathrm{NO}_{3}\right)_{2}, \quad 2 \mathrm{NO}_{2}$ & \\
\hline $\mathrm{CH}_{4}$ & $635-900 P$ & $\mathrm{UC}$ & \\
\hline $\mathrm{CO}$ & 750 & $\mathrm{UO}_{2}$ plus UC & \\
\hline $\mathrm{CO}_{2}$ & 750 & $\mathrm{UO}_{2}$ plus UC & \\
\hline
\end{tabular}

1 refers to massive $U ; P$ denotes powdered $U$ 
oxygen and hydrogen concentrations of the water. The data given in Figure 14 are for hydrogen saturated water--a condition which would quickly obtain in a static system. Oxygen is a strong retardant of $U$ corrosion by water. At $70 \mathrm{C}$, the corrosion rate for hydrogen saturated water is reported to be roughly $20 \mathrm{X}$ that of aerated, oxygen saturated water. ${ }^{(28)}$ Waber $^{(14)}$ proposes that uranium hydroxides, or hydrated oxides, are responsible for the accelerated attack of $U$ in hydrous atmospheres. Oxygen in the water is believed to retard corrosion by reducing hydroxide formation in favor of a protective, hydroxide-free scale layer. This hydroxide hypothesis (also suggested by Huddle ${ }^{(36)}$ ) is, to some extent, an alternative to contentions that $\mathrm{UH}_{3}$ is the critical, stimulative, factor in water and steam corrosion of $\mathrm{U}$. There is considerable evidence that $\mathrm{UH}_{3}$ is formed in the course of water and steam corrosion of $U$ over a wide range of temperatures although there is still poor identification of the physical and chemical conditions conducive to hydride formation. Hydroxides and $\mathrm{UH}_{3}$ would not appear to be mutually exclusive and a complete theory of uranium corrosion by hydrous atmospheres will doubtless have to provide for both of these reaction products. For the purposes of this discussion, the water corrosion of $U$ may be represented by the following, qualitative equations:

$$
\begin{aligned}
\mathrm{U}+\mathrm{H}_{2} \mathrm{O}(1) & \rightarrow \mathrm{UO}_{2}+\mathrm{H}_{2} \text { (low } \mathrm{H} \text {, high } \mathrm{O} \text { environment) } \\
& \left.\rightarrow \mathrm{UO}_{2}+\mathrm{UH}_{3} \text { (high } \mathrm{H} \text {, low } \mathrm{O}\right) \\
& \rightarrow \mathrm{UO}_{2}+\underset{\text { hydrated oxides and/or hydroxides }}{\text { (high } \mathrm{H} \text {, low } \mathrm{O} \text { ) }}
\end{aligned}
$$

These reactions, within certain temperature limits, are probably applicable to the $\mathrm{U}$-steam reaction.

Unfortunately, existing data on steam reactions with $U$ are inconsistent in three important respects: the modes, or laws, of oxidation which operate at various temperatures and at various times under isothermal conditions; the absolute value of the oxidation corresponding to given oxidation circumstances--time, temperature, and atmosphere; the principal oxidation products resulting from given oxidizing conditions. 
The reaction, $\mathrm{U}+2 \mathrm{H}_{2} \mathrm{O} \rightarrow \mathrm{UO}_{2}+2 \mathrm{H}_{2}$, is generally considered to be a satisfactory representation of the $\mathrm{U}$-steam reaction. There is some evidence ${ }^{(37)}$ that $\mathrm{U}_{3} \mathrm{O}_{8}$ becomes increasingly important at temperatures in excess of roughly $250 \mathrm{C}$. As noted above, hydroxides, hydrated oxides, and $\mathrm{UH}_{3}$ are probably also involved at various temperatures. Hopkinson ${ }^{(38)}$ reported the presence of $\mathrm{UH}_{3}$ (at room temperature) after steam oxidation at temperatures as high as $1060 \mathrm{C}$, and noted that the re was greater hydride development, the higher the oxidation temperature. Brugman and Hoxeng ${ }^{(28)}$ stress the importance of the following reactions in steam corrosion of $U$ :

$$
\begin{aligned}
& \mathrm{U}+2 \mathrm{H}_{2} \mathrm{O} \rightarrow \mathrm{UO}_{2}+2 \mathrm{H}_{2} \\
& \mathrm{U}+\frac{3}{2} \mathrm{H}_{2} \rightarrow \mathrm{UH}_{3} \\
& 2 \mathrm{H}_{2} \mathrm{O}+\mathrm{UH}_{3} \rightarrow \mathrm{UO}_{2}+31 / 2 \mathrm{H}_{2}
\end{aligned}
$$

which produce $\mathrm{UH}_{3}$ as well as $\mathrm{H}_{2}$ for the regeneration of $\mathrm{UH}_{3}$. The physical and chemical conditions which delimit the occurrence of $\mathrm{UH}_{3}$ in steam oxidation are, as previously noted, not well known at present. The importance of $\mathrm{UH}_{3}$ to the subject of uranium pyrophoricity justifies a separate, following, section on this compound.

Some indication of the unsatisfactory situation with respect to U-steam reaction data is given in Figure 15, where linear oxidation rate data from various sources are given as a function of temperature. While the linear law is reportedly not strictly applicable to some of the data, effective linear rates--yielding the observed total oxidation for a given exposure time--have been used in Figure 15, and these suffice for purposes of rough comparison. Data from three British sources, Huddle ${ }^{(36)}$, Wathen ${ }^{(37)}$ and Hopkinson ${ }^{(38)}$ are plotted, together with results reported by Lemmon. ${ }^{(39)}$ Some preliminary data obtained by Scott of Hanford Laboratory ${ }^{(40)}$ are also presented. Extent of oxidation was determined either by measuring the metal $\operatorname{loss}(36,37,38,40)$ or by measuring the hydrogen evolved during the reaction. ${ }^{(39)}$ In the latter case, $\mathrm{UO}_{2}$ and $\mathrm{H}_{2}$ were taken as the principal reaction products. There is not sufficient information on the chemical, mechanical, and thermal histories 


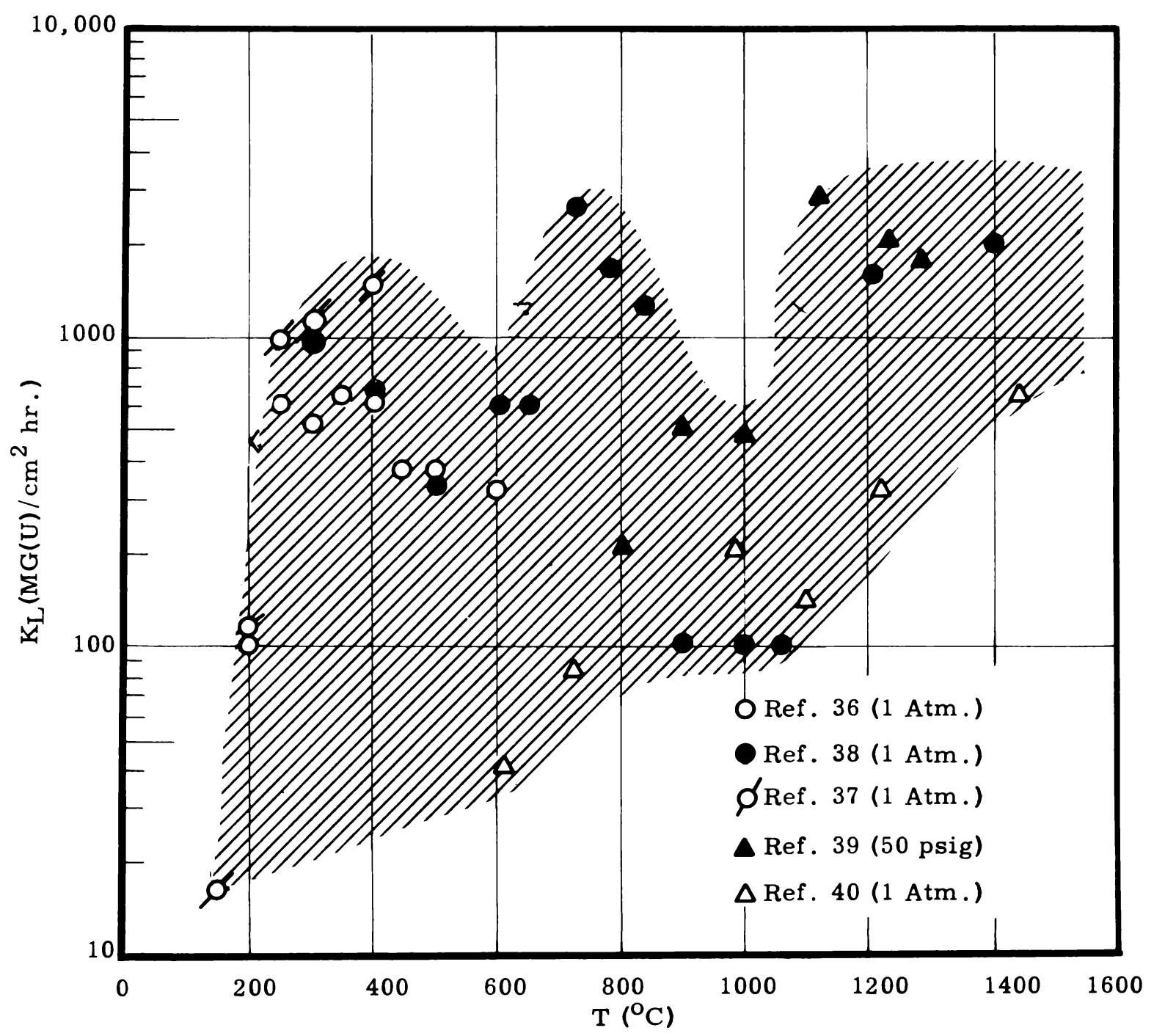

FIGURE 15

$\mathrm{U}$ Corrosion in Steam $=F(T)$ 
of the test materials involved in Figure 15 to permit any judgement as to the possible influence of these variables on the oxidation characteristics of the respective materials. The strongly exothermic reaction involved makes the achievement of an isothermal oxidation condition extremely difficult at the higher temperatures. The rather spectacular disagreement indicated in Figure 15 is, perhaps, attributable as much to uncontrolled temperature variation as to any other factor.

The data of Huddle ${ }^{(36)}$ and Hopkinson (38) indicate that the U-steam reaction rate does not increase monotonically with temperature; but exhibits several maximum below the MP of U. Hopkinson ${ }^{(38)}$ ascribes the maximum near $300 \mathrm{C}$ to the formation of $\mathrm{UH}_{3}$, which, through physical effects, decreases the protective quality of the $\mathrm{UO}_{2} \cdot \mathrm{Huddle}^{(36)}$ attributed the decrease in rate in the range of 300-600 $\mathrm{C}$ to changes in the physical characteristics of the $\mathrm{UO}_{2}$ which increase the resistance of the oxide to oxygen penetration via diffusion paths, or gross structural faults, in the oxide. Hopkinson noted a marked increase in the compactness and adherence of the oxide at temperatures over $800 \mathrm{C}$. The complex shape of the rate-temperature characteristic beyond $600 \mathrm{C}$ was attributed to changes in the physical structure of the $\mathrm{UO}_{2}$.

Huddle cites unpublished British data indicating that a hydrous atmosphere increases the tendency of $\mathrm{UO}_{2}$ to sinter, with the implication that sintering increases the protective value of the oxide. Antill ${ }^{(41)}$ states that appreciable $\mathrm{UO}_{2}$ sintering is not observed at temperatures below about $1300 \mathrm{C}$. He attributes the development of structurally sound $\mathrm{UO}_{2}$ at lower temperatures more to an increase in the plasticity of the oxide than to sintering. It was noted previously that there was surprisingly little evidence of $U$ oxidation during the course of the $\mathrm{K}$ reactor incident. (25) The British data, indicating that a marked diminution in oxidation rate occurs over certain temperature ranges (of Figure 15), was invoked in explanation of this occurrence. Free energy data for the $\mathrm{U}-$ steam and $\mathrm{U}-\mathrm{O}_{2}$ reactions, calculated by Huddle ${ }^{(36)}$, indicate that $U$ would react preferentially with $O$ in a steam atmosphere containing free oxygen--assuming comparable activation energies are involved. 
Air contamination of steam could possibly effect a significant alteration in the physical characteristics of the oxide layer, manifested by changes in the apparent steam oxidation rate. Scott ${ }^{(40)}$ has suggested this as a possibie factor in the discrepancies seen in Figure 16. The U-steam reaction would be expected to show some positive sensitivity to steam pressure--assuming some parallelism to the $\mathrm{U}-\mathrm{O}_{2}$ reaction, which has shown a positive rate of change with respect to pressure. The data of Lemmon ${ }^{(39)}$, given in Figure 15, were taken at 50 psi. Possibly some of the difference between these data and those of Scott is attributable to pressure effects. The reaction may also be influenced by the partial pressure of hydrogen in the steam if hydrogen involvement in the corrosion products is affected by this factor. There is little, or no, quantitative information of significance on these effects.

Huddle's ${ }^{(36)}$ calculations of the heat release from the U-steam and $\mathrm{U}-\mathrm{O}_{2}$ reactions are given in Figure 16. Any estimate of the rate of heat release from the $U$-steam reaction is rendered highly speculative by the present uncertainty with respect to the $\mathrm{U}$-steam reaction kinetics.

\section{Uranium-Hydrogen}

The reaction between a metal and water, or steam, generates hydrogen according to the following qualitative reactions:

$$
\begin{aligned}
\mathrm{xM}+\mathrm{yH}_{2} \mathrm{O} \rightarrow \mathrm{M}_{\mathrm{X}} \mathrm{O}_{\mathrm{Y}}+\mathrm{H}_{2}+ & (\mathrm{H} \text { absorbed by metal in solution) } \\
+ & (\mathrm{H} \text { incorporated in metal } \\
& \text { hydrides, hydroxides, and/or } \\
& \text { hydrated oxides }) \\
+ & (\mathrm{H} \text { incorporated in oxide as ions } \\
& \text { or neutral atoms and molecules })
\end{aligned}
$$

The relative importance of the several alternative disposition schemes depends on the oxidation conditions. There are three potential activities of hydrogen which could qualify this element as an important intermediary, or direct participant, in reactor fire and explosion events. First, free hydrogen, generated by a metal-water reaction, can constitute a serious explosion hazard to local core regions, or the general reactor system, depending on the conditions of confinement, hydrogen density, and the 


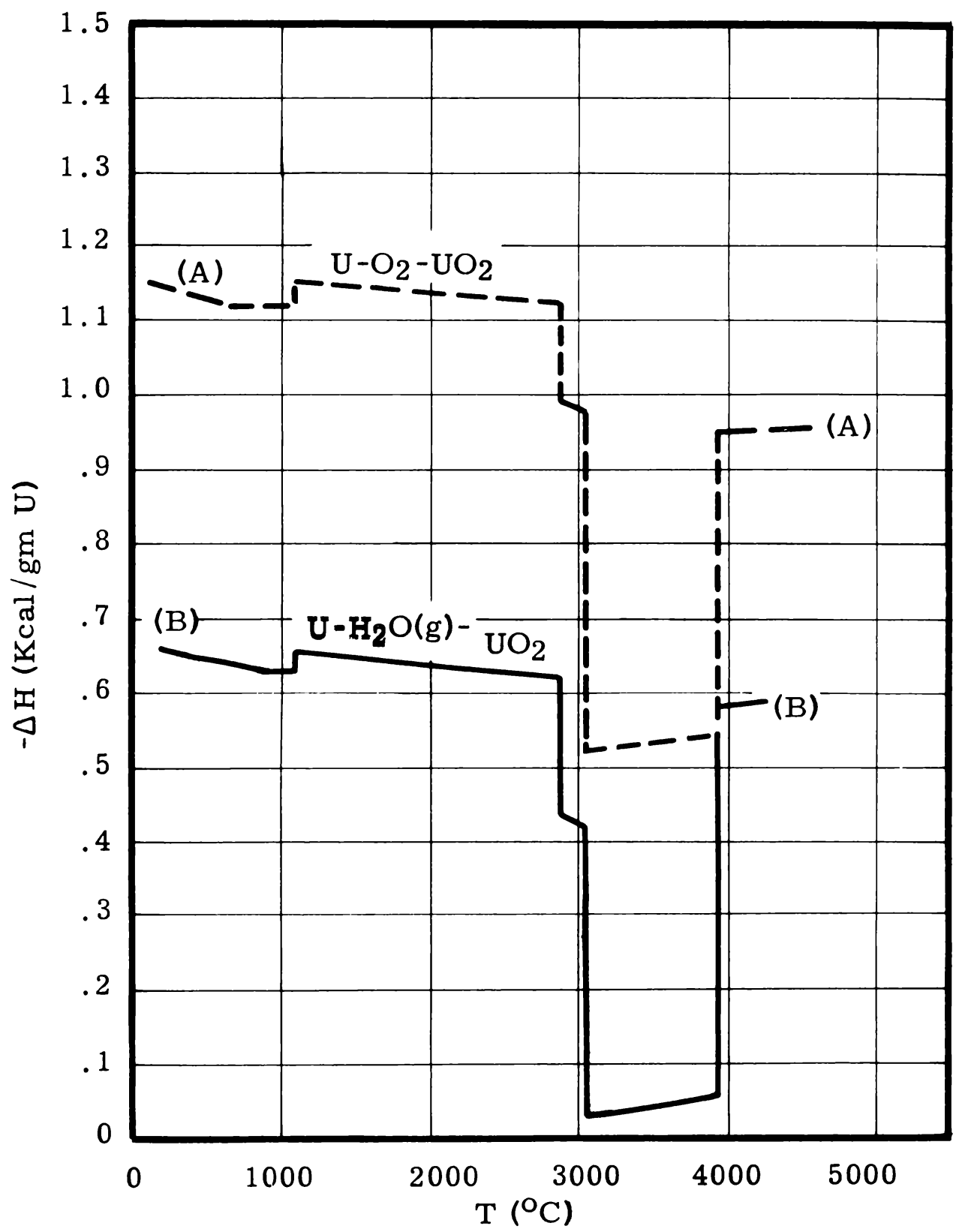

FIGURE 16

Heat Release from U-Steam and $\mathrm{U}-\mathrm{O}_{2}$ Reactions $=$ $F(T)$ (Ref. 36) 
dilution by air and inerts. A subsidiary consequence of a hydrogen explosion might be the creation of a dispersion of molten metal which could, in turn, significantly augment the chemical power release from a fire, or explosion, incident. While the conditions under which a potentially hazardous quantity of hydrogen could develop are perhaps within the purview of the present discussion, the hydrogen hazard, by itself, is of sufficient scope to justify a separate report. Second, hydrogen disposed at the metaloxide interface or within the oxide in chemical combination with the oxidation participants, or in elemental form, can markedly affect the oxidation rate of the metal. As noted previously, hydrides, and hydroxides, have been proposed as critical intermediaries in the rapid attack of uranium by steam, or water. Apart from increasing the rate of structural degradation of core components, an increased oxidation rate adds to the burden of the environmental cooling facilities in preventing an energy excursion. Third, the formation of uranium hydride increases the fire potential associated with uranium in two ways, namely; by the creation of a uranium compound which, through its propensity to revert to powder from, and its inherent reactivity, is a highly pyrophoric substance; by the generation of powdered highly active, uranium through the thermal decomposition of the hydride under certain $\mathrm{P}$ and $\mathrm{T}$ conditions. Because of the importance of $\mathrm{UH}_{3}$ to uranium pyrophoricity, some attention to the properties of $\mathrm{UH}_{3}$ and the conditions for its formation is in order.

Two hydrides of $U$ have been reported, commonly designated the delta and epsilon phases--both having the formula $\mathrm{UH}_{3}{ }^{(33)}$ The epsilon form is the one generated at temperatures of significance to the present discussion. Warf ${ }^{(10)}$ and co-workers at the Ames laboratory, have presented several comprehensive summaries of the properties of $\mathrm{UH}_{3}$. Some appreciation for the reactivity of this compound may be had from Table IX which incorporates some of the findings reported by Warf. The difficulty of assigning a pyrophoricity index has been noted above. The reactivity of $\mathrm{UH}_{3}$ described by Warf, as well as the powder ignition work previously cited ${ }^{(7)}$, clearly identify $\mathrm{UH}_{3}$ as a dangerous material. It has been demonstrated that $\mathrm{UH}_{3}$ has a reactivity with water, air, and steam which, coupled 
TABLE IX

\section{REACTIVITY OF $\mathrm{UH}_{3}$}

(Reference 10)

\section{$\underline{\text { Reactant }}$}

$\mathrm{O}_{2}$

$\mathrm{N}_{2}$

$\mathrm{H}_{2} \mathrm{O}$

Steam

$\mathrm{CO}_{2}$

$\mathrm{HNO}_{3}$

$\mathrm{CCl}_{4}$
Product

$\mathrm{H}_{2} \mathrm{O}, \mathrm{U}_{3} \mathrm{O}_{8}$

Nitride, $\mathrm{H}_{2}$

$\mathrm{UO}_{2}, \mathrm{H}_{2}$

$\mathrm{UO}_{2}, \mathrm{H}_{2}$

$\mathrm{UO}_{2}, \mathrm{C}$ or carbide

Uranyl nitrate oxides of nitrogen

Uranyl chloride, $\mathrm{C}, \mathrm{HCl}$
Comments

Ignition can occur at temperatures as low as $-76 \mathrm{C}$

Fairly rapid reaction at $250 \mathrm{C}$; ignition will continue in $\mathrm{N}_{2}$ after initial combustion in air

Reaction proceeds at, or below, R.T. Violence depends on relative a mounts and rate of contact of water and hydride

Rapid reaction; can cause mass of $\mathrm{UH}_{3}$ to reach luminescence

Fairly rapid at $\mathrm{R}$. T. , rapid at $300 \mathrm{C}$; combustion initiated in air can be sustained in $\mathrm{CO}_{2}$

Violent reaction; explosion and ignition possible

Violent reaction; explosion and ignition possible

Products of thermal decomposition of $\mathrm{UH}_{3}$

250-300 C: finely divided $\mathrm{U}$ (very reactive) plus $\mathrm{H}_{2}$

450-500 C: hard, coarse $\mathrm{U}$ particles plus $\mathrm{H}_{2}$

$900 \mathrm{C}$ : massive $\mathrm{U}$ metal aggregate plus $\mathrm{H}_{2}$ 
with the strong potential for formation of this compound under certain reactor conditions, justifies present contentions that $\mathrm{UH}_{3}$ is a prime factor in fuel element fires. In addition to the inherent reactivity of $\mathrm{UH}_{3}$, this compound shows a tendency to revert to powder form after removal of the ambient hydrogen atmosphere. $(10,42)$ in the temperature range 250-300 C, thermal decomposition of $\mathrm{UH}_{3}$ generates a finely divided $\mathrm{U}$. It is seen that both the formation and the decomposition of this compound tend to increase the pyrophoric potential of the affected environment.

The hydriding and dissociation reactions under discussion may be stated,

$$
\begin{gathered}
\text { Hydriding } \\
\mathrm{U}+3 / 2 \mathrm{H}_{2} \stackrel{\rightleftarrows}{\mathrm{UH}_{3}}
\end{gathered}
$$

Dissociation

which is a specific case of the following, more general, qualitative statement of the $\mathrm{U}-\mathrm{H}$ reaction giving possible reaction products:

$$
\begin{aligned}
\mathrm{U}+\mathrm{H}_{2} & \rightarrow \mathrm{UH}_{3} \\
& \rightarrow \mathrm{UH}_{3}(\mathrm{U})+\mathrm{U}(\mathrm{H}) \\
& \rightarrow \mathrm{U}(\mathrm{H})
\end{aligned}
$$

where $\mathrm{UH}_{3}(\mathrm{U})$ and $\mathrm{U}(\mathrm{H})$ represent solid solutions of uranium in $\mathrm{UH}_{3}$ and hydrogen in a uranium matrix, respectively. The products from a $\mathrm{U}-\mathrm{H}$ reaction depend on the temperature, as well as the pressure of the ambient hydrogen gas. Within its stability range, each product has an equilibrium hydrogen pressure $\left(\mathrm{p}_{\mathrm{H}}^{\mathrm{O}}\right)$, fixed by the product and the temperature. When this pressure is varied, the composition, or identity, of the solid product tends to adjust to the new pressure level. The equilibrium, or dissociation, pressure of $\mathrm{UH}_{3}$ exhibits a rapid rise with temperature and at temperatures in excess roughly $250 \mathrm{C}$, rapidly attains a significant magnitude with respect to hydrogen pressures which might obtain in a working environment. The practical consequence of this is that, within the temperature range of present interest, the kinetics of formation of $\mathrm{UH}_{3}$, as well as the phase relitionships of the U-H system, are strongly sensitive to the ambient hydrogen pressure. 
The work of Warf ${ }^{(10)}$, Albrecht, and Mallet ${ }^{(42,43)}$, Mallet and Trzeciak ${ }^{(44)}$, and Gibb ${ }^{(45)}$ has contributed to an understanding of this fairly complex situation. Consider a quantity of $\mathrm{UH}_{3}$ at a given temperature and under a hydrogen pressure which exceeds, or equals, the dissociation pressure $\left(\mathrm{p}_{\mathrm{H}}^{\mathrm{o}}\right)$ corresponding to the given temperature (T). Two variations of the system parameters are of interest, namely: a decrease of the $\mathrm{H}_{2}$ pressure $\left(\mathrm{p}_{\mathrm{H}}\right)$ at constant $\mathrm{T}$; an increase in the $\mathrm{T}$ at constant $\mathrm{p}_{\mathrm{H}}$. Both variations will cause some decomposition of the $\mathrm{UH}_{3}$ when the $\mathrm{H}_{2}$ pressure falls below the equilibrium pressure of $\mathrm{UH}_{3}$ at the prevailing temperature. The $\mathrm{UH}_{3}$ decomposition will first generate a dilute solution of uranium in $\mathrm{UH}_{3} \mathrm{JUH}_{3}(\mathrm{U})$, usually written $U_{\mathrm{X}}$, with $\mathrm{x}$ less than 3). As the differential between the ambient $\mathrm{H}_{2}$ pressure and $\mathrm{p}_{\mathrm{H}}^{\mathrm{O}}$ for pure $\mathrm{UH}_{3}$ increases, further dilution of the $\mathrm{UH}_{3}$ by uranium will occur (i.e., $\mathrm{x}$ decreases). A continued variation of $\mathrm{p}_{\mathrm{H}}$ or $\mathbf{T}$, as above, will eventually create a second phase--a terminal solid solution of hydrogen in uranium in equilibrium with $\mathrm{UH}_{\mathrm{x}^{\circ}}$ Variation beyond this point will effect disappearance of the $\mathrm{UH}_{\mathrm{x}}$, the prevailing phases becoming gaseous hydrogen and a solid solution of hydrogen in uranium--of decreasing $\mathrm{H}$ content. These decomposition reactions will, as noted previously, yield finely divided uranium, which, upon sudden exposure to an oxidizing atmosphere, can oxidize with explosive violence, or at a sufficient rate to cause ignition. The formation of $\mathrm{UH}_{3}$ is of equal interest to the present review and essentially the above variations, with reversed trends of $p_{H}$ and $T$, will provide a qualitative description of the formation of $\mathrm{UH}_{\mathrm{x}}$, or $\mathrm{UH}_{3}$, from the starting point of metallic uranium and gaseous hydrogen. Some indication of the dependence of these formation and decomposition reactions on $\mathrm{p}_{\mathrm{H}}$ and $\mathrm{T}$ is given in Figure 17, based on data from References 44 and 45.

The authors previously cited have studied the kinetics of formation of $\mathrm{UH}_{3}$ over wide ranges of $\mathrm{T}$ and $\mathrm{p}_{\mathrm{H}}$. Both Warf ${ }^{(10)}$ and Albrecht ${ }^{(42)}$ report a short induction period after exposure of $\mathrm{U}$ to $\mathrm{H}_{2}$ before start of hydriding. Warf states that oxygen contamination of the $\mathrm{H}_{2}$ will retard the hydriding reaction. The presence of oxide on the metal, per se, reportedly is less of a barrier to hydriding than oxygen in the ambient atmosphere. 


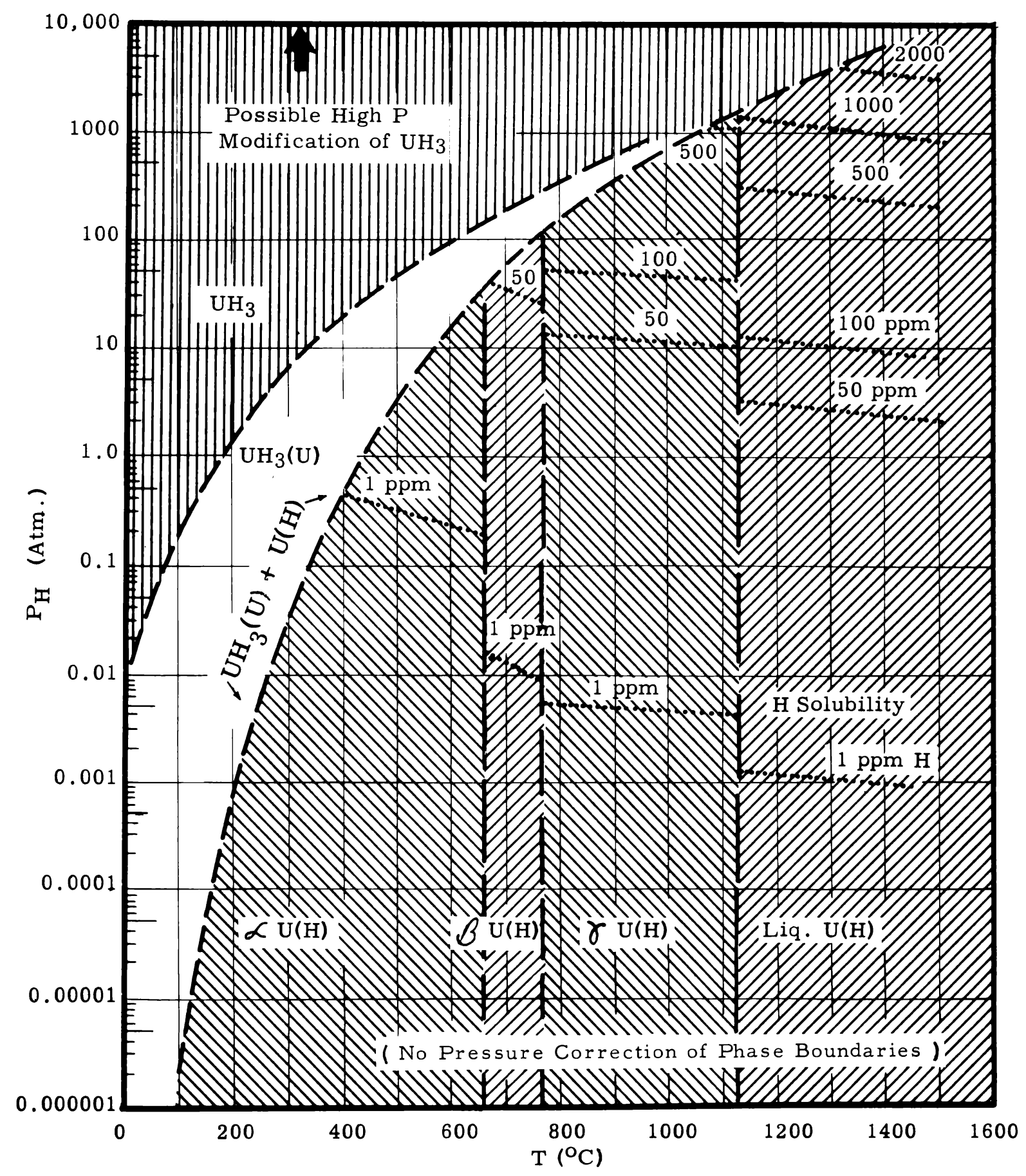

FIGURE 17

Existence Ranges of Various U-H Reaction Products $=F\left(p_{H}, T\right)$ 
These observations indicate a noteworthy similarity between the hydriding characteristics of uranium and zirconium. ${ }^{(29)}$ Following the induction period, Albrecht and Mallett observed a linear reaction rate, although some tendency for development of a protective hydride was noted for certain $\mathrm{p}_{\mathrm{H}}$ and $\mathrm{T}$ conditions. At temperatures below roughly $250 \mathrm{C}$ and $\mathrm{H}_{2}$ pressures ranging from 70 to $430 \mathrm{~mm}$, these authors found that the linear reaction rate followed the relation,

$$
\mathrm{k}_{1}=4.11 \times 10^{-3} \mathrm{p}_{\mathrm{H}} 3 / 4 \exp \left(\frac{-1820}{\mathrm{RT}}\right)
$$

where $\mathrm{k}_{1}$ is the linear rate in $\mathrm{ml}(\mathrm{STP}) \mathrm{cm}^{-2} \mathrm{sec}^{-1}, \mathrm{p}_{\mathrm{H}}$ is in $\mathrm{mm}, \mathrm{T}$ is ${ }^{\circ} \mathrm{K}$. As the decomposition pressure approached the ambient $\mathrm{H}_{2}$ pressure, a maximum reaction rate was observed, followed by a decrease in the rate as $\mathrm{p}_{\mathrm{H}}-\mathrm{p}_{\mathrm{H}}^{\mathrm{o}}$ approached zero. At $375 \mathrm{C}$ (where $\mathrm{p}_{\mathrm{H}}^{\mathrm{o}}$ is about $135 \mathrm{~mm}$ ) the initial reaction rate between $U$ and $\mathrm{H}_{2}$ is reported to be proportional to $\left(\mathrm{p}_{\mathrm{H}}-\mathrm{p}_{\mathrm{H}}^{\mathrm{o}}\right)$ to the $5 / 2$ power. ${ }^{(33)}$ These observations are cited to indicate that the simple pressure dependence expressed by Equation 16 is not valid when $\mathrm{p}_{\mathrm{H}}$ and $\mathrm{p}_{\mathrm{H}}^{\mathrm{O}}$ are of comparable magnitude. Using data from previous studies 43,45 ), Albrecht and Mallett ${ }^{(44)}$ calculated reaction rate data for the formation of $\mathrm{UH}_{3}$ and various $\mathrm{UH}_{\mathrm{x}}$ products under equilibrium pressures of hydrogen. The linear rate data for $\mathrm{UH}_{3}$, as well as $\mathrm{p}_{\mathrm{H}}^{\mathrm{O}}$ data for $\mathrm{UH}_{3}$, are given as a function of temperature in Figure 18. To some extent, these data are hypothetical and are intended only as a rough index of the formation rate of $\mathrm{UH}_{3}$ under various $\mathrm{p}_{\mathrm{H}}$ and $\mathrm{T}$ conditions.

Equilibrium data suffice only as a rough guide to the identity and composition of corrosion products on metals during various stages of the attack. Transient, non-equilibrium phases--unpredictable from equilibrium studies--can prevail during the course of a metal-gas reaction. There would appear to be some uncertainty in this respect with the $\mathrm{U}-\mathrm{H}$ reaction. From the standpoint of fire hazard, it would probably be trivial to discriminate among the various hydride compositions which could form from a $\mathrm{U}-\mathrm{H}$ reaction.

Brugman and Hoxeng ${ }^{(28)}$ have described the formation of $\mathrm{UH}_{3}$ within cladding-fuel core assemblies after creation of a cladding bond defect which 


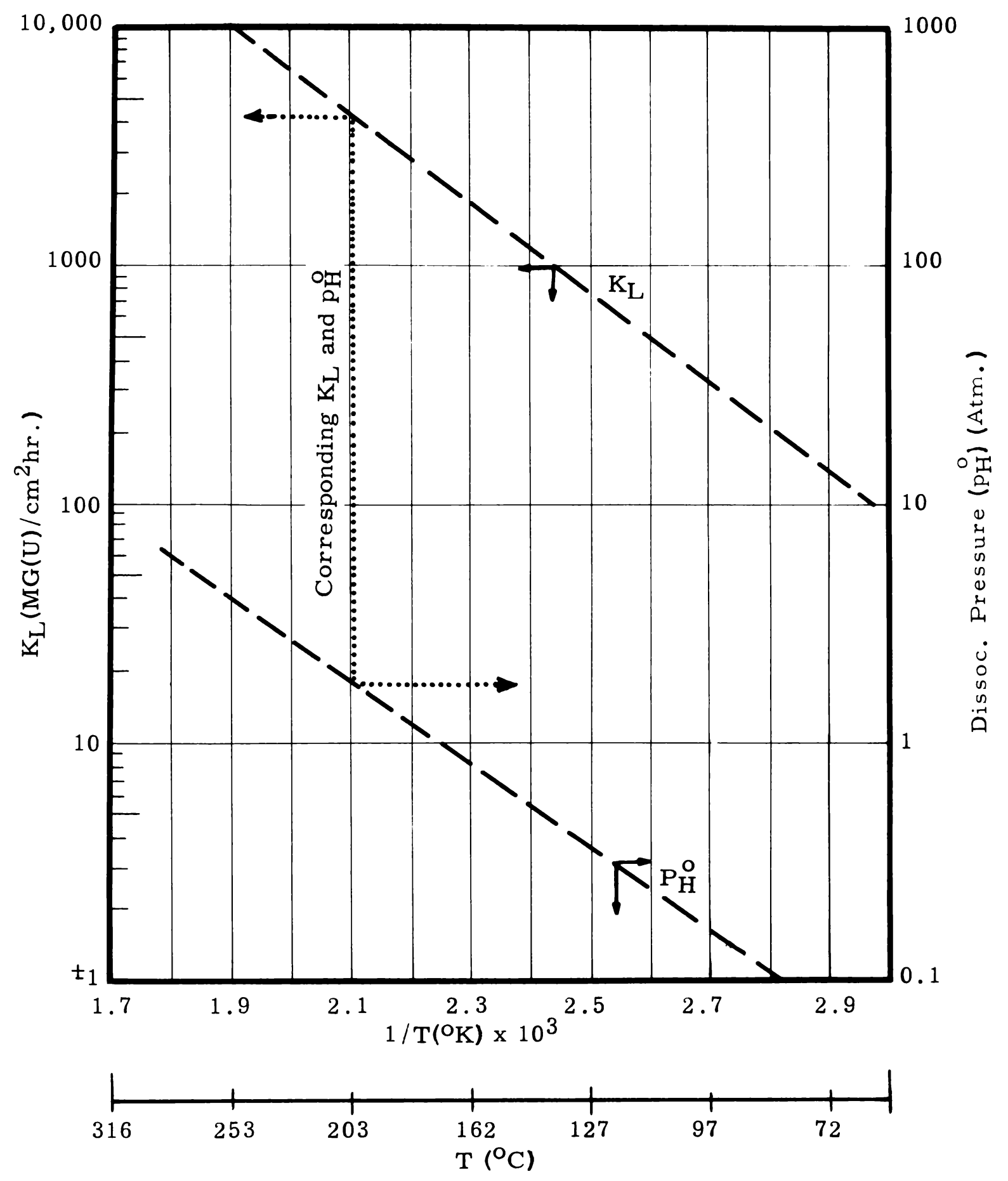

FIGURE 18

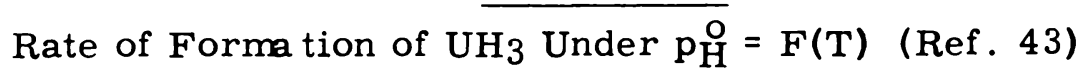


permits oxidation of the uranium. The chemical reactions believed to be involved were previously given in conjunction with steam corrosion(Eq. 13). Hydrogen generated from the $\mathrm{U}-\mathrm{H}_{2} \mathrm{O}$ reaction and the oxidation of $\mathrm{UH}_{3}$ migrates along gross structural faults--usually at the core-cladding interface--until conditions are propitious for the formation of $\mathrm{UH}_{3}$. This "hydrogen front" creates pockets of $\mathrm{UH}_{3}$ (as well as other $\mathrm{U}-\mathrm{H}$ reaction products, previously mentioned) along the migration path, whose stability is determined by the local $\mathrm{p}_{\mathrm{H}}$ and $\mathrm{T}$ conditions, as well as the rate of advance of the oxidizing atmosphere. Thermal decomposition of hydride pockets will, in the absence of succeeding oxidation, generate highly active, finely divided, uranium--virtually equivalent to $\mathrm{UH}_{3}$ from a fire standpoint. The formation of blisters, or dimples, in an almost regular sequence away from the original cladding defect, is a well known phenomenon. The sudden exposure of these zones of hydride, or powdered uranium from the decomposition of hydride, by an action such as shearing of a process tube, creates an ideal fire situation. It is believed that the majority of fuel element fires in Hanford reactors has been attributable to the sequence of events described above. E. A. Smith ${ }^{(46)}$ and M. L. Smith ${ }^{(47)}$ of Hanford have presented analyses in support of this argument. The ability of a fuel element to sustain combustion after exhaustion of the original active center(s), would depend on the temperature and physical condition of the element as well as environmental cooling and oxidation factors.

\section{Uranium- $\mathrm{CO}_{2}$}

The $\mathrm{U}-\mathrm{CO}_{2}$ reactions are considered here for two reasons: first, structural decay of a process tube which permitted contact between fuel elements and the stack gas would probably involve some $\mathrm{U}-\mathrm{CO}_{2}$ reaction (in Hanford reactors). Second, as previously noted, $\mathrm{CO}_{2}$ appears to have considerable potential for preventing $\mathrm{H}_{2}$-air explosions. Some utility in quenching $U$ fires has also been indicated. ${ }^{(48)}$ On these counts, the use of $\mathrm{CO}_{2}$ as a flush gas merits some consideration.

The $\mathrm{U}-\mathrm{CO}_{2}$ reaction has been considered in a recent report by Antill. (41) This reaction may be represented qualitatively as follows: 


$$
\begin{aligned}
\mathrm{U}+\mathrm{CO}_{2} & \rightarrow \mathrm{UO}_{2}+\mathrm{CO} \\
& \rightarrow \mathrm{UO}_{2}+\mathrm{C} \text { (as free } \mathrm{C} \text {, or uranium carbides) }
\end{aligned}
$$

The relative importance of these alternative reaction schemes, as a function of temperature, is not well known. Antill reports that $\mathrm{UO}_{2}$ is the predominant oxide up to the temperature limit of his tests--1000 C. The heat release from the above reactions, coupled with the increased reaction rate at high temperatures, introduces considerable difficulty in establishing the oxidation rate-temperature correspondence at the high temperature levels. With cylindrical specimens $(2.5 \mathrm{~cm}$ long $\times 2 \mathrm{~cm}$ dia. $)$, Antill detected the onset of a significant differential between the specimen and gas temperatures at a gas temperature of about $725 \mathrm{C}$. This differential expanded with increase in the gas temperature. At about $775 \mathrm{C}$ gas temperature, the specimen exhibited a marked temperature excursion-jumping about $150 \mathrm{C}$. These temperature values are, to a considerable extent, sensitive to the specific environmental and specimen conditions. They are, therefore, of less significance to the present discussion than the fact that they manifest a strong reactivity between $\mathrm{U}$ and $\mathrm{CO}_{2}$ at temperatures above roughly $700 \mathrm{C}$.

Antill reports a linear reaction dependence over the temperature range 500-1000 C. His data suggest that a "breakaway" phenomenon may be operative--with the initial linear rate changing to a higher linear rate after a certain time. The reported reaction rate data are given in Figure 19 as a function of temperature. These data presumably represent averages where two, or more, separate reaction regimes were involved at a given temperature. The decreasing reaction rate at temperatures above roughly $800 \mathrm{C}$ is noteworthy. Hopkinson's study ${ }^{(38)}$ of the U-steam reaction showed a similar phenomenon. Both sintering of the oxide and increased oxide plasticity--with an enhanced ability to resist growth stresses--have been mentioned as possible explanations of this increased oxidation resistance of $\mathrm{U}$ above roughly $800 \mathrm{C}$.

Water vapor concentrations of the order of $0.05 \mathrm{v} / \mathrm{o}$ had no significant effect on the reaction rate with $\mathrm{CO}_{2}$ at $500 \mathrm{C}$ while $3.1 \mathrm{v} / \mathrm{o}$ water 


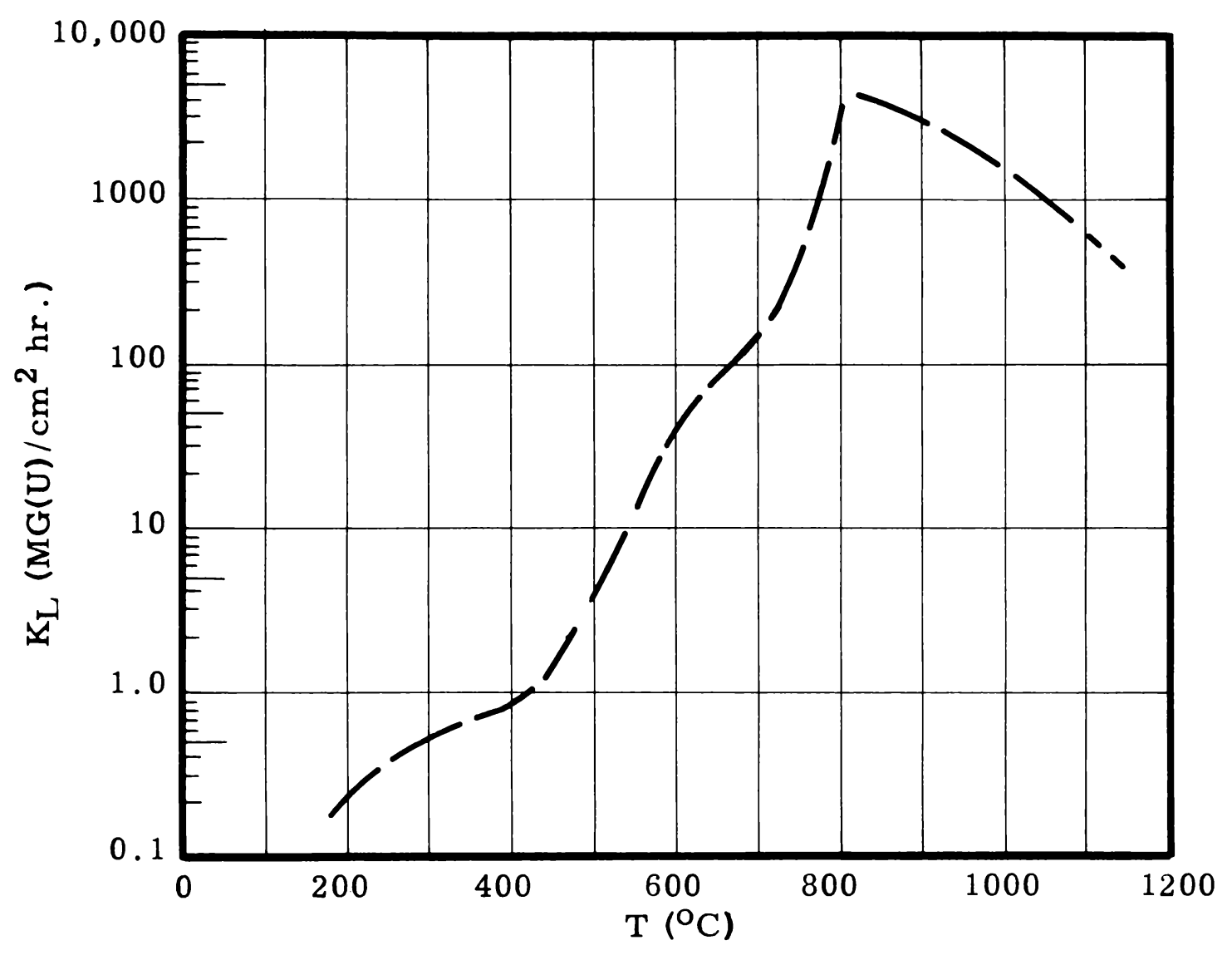

FIGURE 19

Corrosion Rate of $\mathrm{U}$ in Dry $\mathrm{CO}_{2}=\mathrm{F}(\mathrm{T})$

(Ref. 41) 
vapor increased the oxidation rate at this temperature by a factor of eight. This latter concentration of water vapor had little effect at temperature of 850 and $1000 \mathrm{C}$.

\section{Uranium-Air}

The oxidation characteristics of $U$ and $U$ corrosion products in air will affect the temperature history of a fuel element in the interval between contact with air (within, or outside the process tube) and discharge into the retention basin. The $\mathrm{U}$-air reaction may be expressed qualitatively as follows:

$$
\begin{aligned}
& \mathrm{U}+\mathrm{O}_{2} \rightarrow \mathrm{UO}_{2}(\mathrm{~T}<\sim 200 \mathrm{C}) \\
& \mathrm{U}+\mathrm{O}_{2} \rightarrow \mathrm{U}_{3} \mathrm{O}_{8}(\mathrm{~T}>\sim 200 \mathrm{C})
\end{aligned}
$$

The existence ranges of $\mathrm{UO}_{2}$ and $\mathrm{U}_{3} \mathrm{O}_{8}$, as well as other possible oxidation products, are still open to question. The above rough temperature limits are based on work of Wathen ${ }^{(37)}, W^{2}{ }^{(13)}$, and Huddle. ${ }^{(36)}$ At high temperatures, some nitride formation may occur, but the $\mathrm{U}-\mathrm{O}_{2}$ reaction predominates in the reaction of $U$ with air. The presence of nitrogen has been shown ${ }^{(48)}$ to affect the ignition characteristics of $U$. Below about $700 \mathrm{C}$, however, the $\mathrm{U}$-air and $\mathrm{U}-\mathrm{O}_{2}$ reactions appear to be practically equivalent.

The initial $\mathrm{U}-\mathrm{O}_{2}$ reaction appears to follow the parabolic law $\left(w^{2}=k t\right)$. After a time, which decreases rapidly with temperature, subsequent oxidation has been reported as linear $(w=k t)$, or sub-linear $\left(\mathrm{w}=k \mathrm{t}^{\mathrm{n}}\right.$, where $\left.\mathrm{n}>1\right) \mathrm{.}^{(13)}$ Some air oxidation data from various sources $(28,36,37,48)$ are given in Figure 20 . The self-heating propensity, previously mentioned in connection with steam oxidation, is even stronger in oxygen environments. These data suffice only as a rough indication of the oxidation rate at high temperatures. Where two stage oxidation was reported, the effective linear rate over a period of one hour was computed and used for the plot. Heat of reaction data given by Huddle ${ }^{(36)}$ for the $\mathrm{U}-\mathrm{O}_{2}-\mathrm{UO}_{2}$ reaction were presented in Figure 16. Lack of reliable high temperature data for $\mathrm{U}_{3} \mathrm{O}_{8}$ apparently discouraged calculation of the heat 


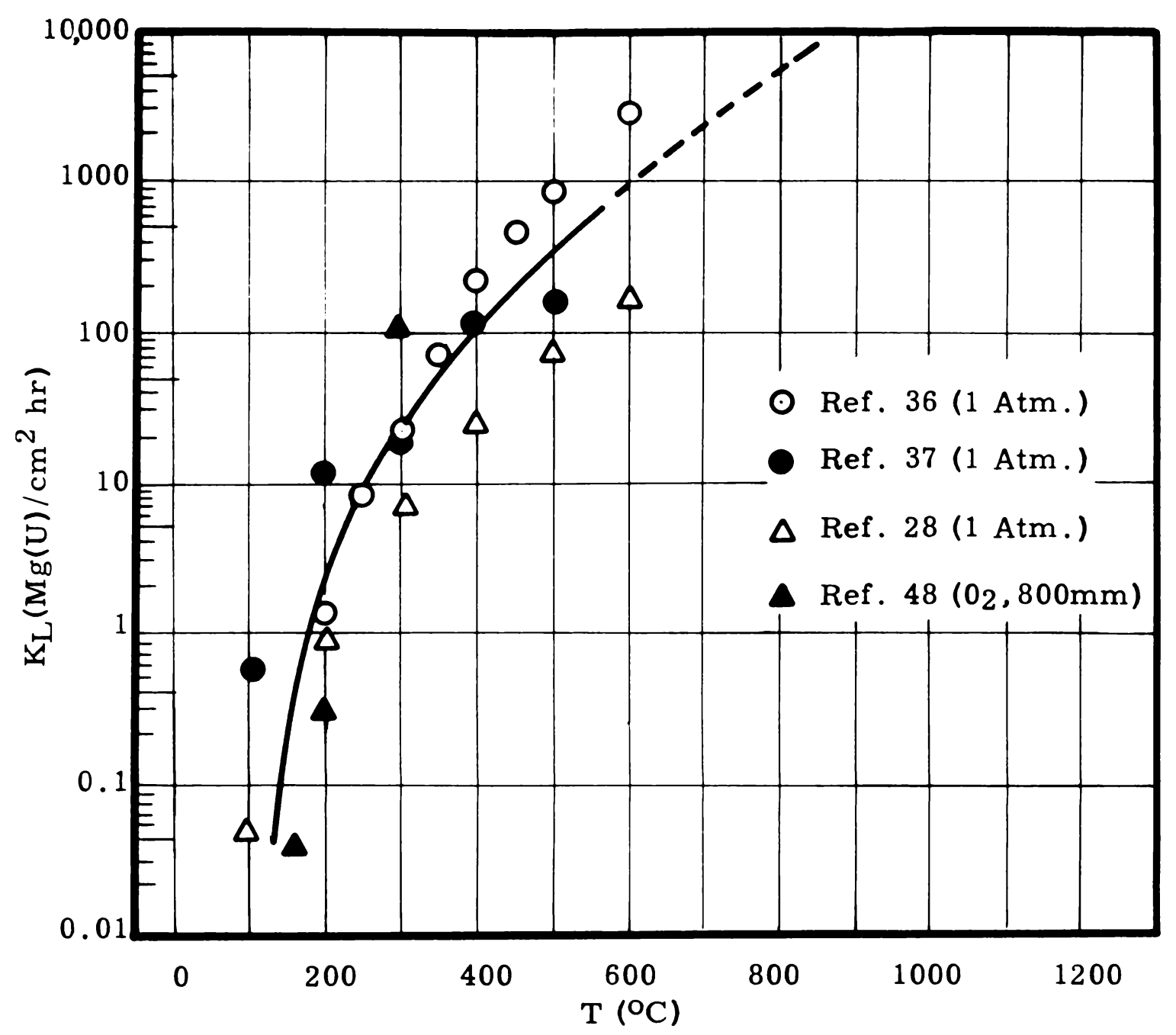

FIGURE 20

Corrosion Rate of $U$ in Air $=F(T)$ 
release from the $\mathrm{U}-\mathrm{O}_{2}-\mathrm{U}_{3} \mathrm{O}_{8}$ reaction, which would be expected to become increasingly significant above roughly $200 \mathrm{C}$.

Some dilution of air by water vapor would be expected in the discharge environment of a fuel element. The $U$-air reaction is stimulated by the presence of water vapor, although quantitative data on this effect are sparse. Waber ${ }^{(13)}$ reports that the greatest influence of water vapor occurs at a concentration equivalent to one per cent relative humidity. This is at some variance with ANL results ${ }^{(48)}$ which indicate that, for temperatures of the order of $200 \mathrm{C}$, the water vapor influence is negligible below about three per cent relative humidity and increases steadily as the relative humidity approaches 100 per cent. The second stage oxidation rate was increased by a factor of 2.5, relative to dry air, at 100 per cent relative humidity. Brugman and Hoxeng ${ }^{(28)}$ state that the U-air reaction is particularly sensitive to water vapor at $285 \mathrm{C}$. These effects have been attributed to hydrogen involvement in the corrosion products and, as noted previously, are little understood.

The $\mathrm{U}-\mathrm{O}_{2}$ reaction shows some sensitivity to oxygen pressure. High temperature data on pressure effects are lacking. Argonne National Laboratory work ${ }^{(48)}$, employing $\mathrm{p}$ and $\mathrm{T}$ ranges of 20-800 $\mathrm{mm}$ and 125$250 \mathrm{C}$, respectively, suggest a pressure influence of the type,

$$
\mathrm{k}_{1}=\mathrm{kp}^{\mathrm{a}}
$$

where (a) is a function of temperature. Values of the exponent for the first stage rates increased from 0.09 to 0.47 over the above $\mathrm{T}$ range, while the exponent corresponding to the second stage rate exhibited a similar change: 0.04 to 0.41 .

Reaction rate data for uranium in steam, $\mathrm{CO}_{2}$, and air are summarized in Figure 21.

\section{URANIUM IGNITION STUDIES}

Although within recent years there has been considerable lip service to the problem of pyrophoricity, the programs oriented toward better understanding of this phenomenon have been few. For several years, ANL has engaged in a comprehensive study of the ignition characteristics of various reactor metals--including $\mathrm{U}, \mathrm{Zr}, \mathrm{Pu}$, and $\mathrm{Th}$. The status of 


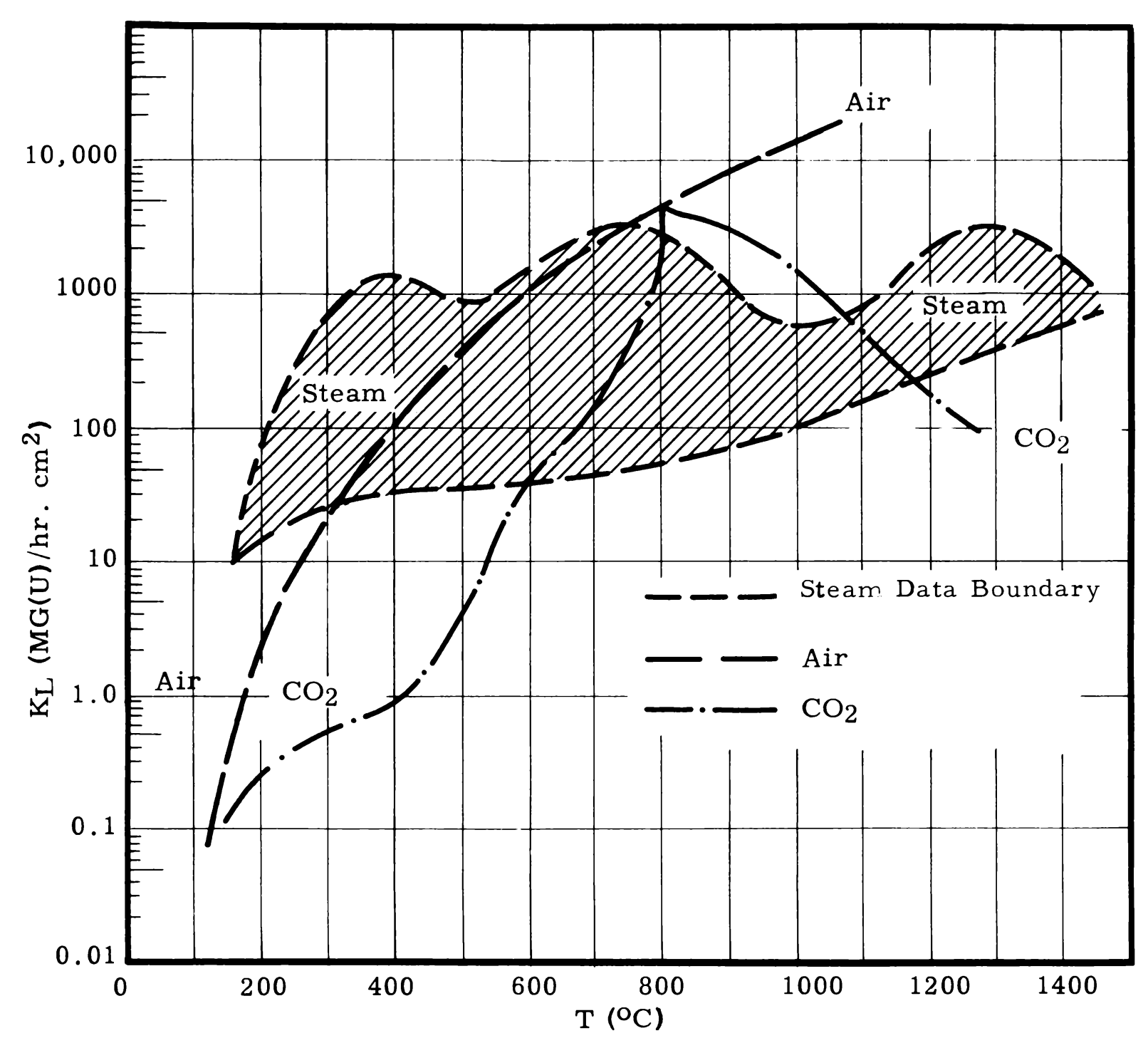

FIGURE 21

Summary U Corrosion Rates in Steam, Air, $\mathrm{CO}_{2}=-\mathrm{F}(\mathrm{T})$ 
this program was summarized in a recent report. (48) A brief summary of the findings of this work, related to $U$ and uranium alloys, is given below.

The ANL program has employed essentially four different tests in an attempt to identify the controlling variables in ignition phenomena, namely: conventional, isothermal, oxidation tests; "burning curve" tests, wherein the specimen is exposed to the oxidizing environment throughout its temperature history and the heat input to the specimen is adjusted to yield a constant rate of temperature rise $(10 \mathrm{C} / \mathrm{min})$; "shielded ignition" tests wherein the specimen is heated to a predetermined temperature in an inert atmosphere and then the test atmosphere is introduced to the specimen; ignition propagation tests, wherein ignition of foil strips is initiated by an electric heater, and the rate of longitudinal advance of the ignition front is monitored by high speed photography. In both the burning curve and shielded ignition tests, the specimen temperature corresponding to the onset of a sustained specimen temperature excursion is designated the ignition temperature $\left(\mathrm{T}_{\mathrm{ig}}\right)$. The maximum temperature attained by the specimen during the course of the ignition was designated the burning temperature.

Present uncertainty regarding the complex dependence of ignition characteristics on environmental and specimen factors seriously limits the practical significance of laboratory ignition data. The ANL program has identified several new effects and reaffirmed the importance of several factors which have long been accorded prime importance in ignition phenomena. These results may be summarized under two headings: influence of specimen factors; influence of environmental factors.

\section{A. Influence of Specimen Factors}

With a given atmosphere and type of specimen, the burning curve and shielded ignition tests yielded reasonably consistent data. Ignition temperature data derived from the burning curve technique--using flowing oxygen at one atmosphere pressure--were correlated with the specific area of the specimen as follows:

$$
\log A_{\mathrm{p}}^{*}\left(\mathrm{~cm}^{2} / \mathrm{gm}\right)=4190 / \mathrm{T}_{\mathrm{ig}}\left({ }^{\circ} \mathrm{K}\right)-5.23
$$


The magnitudes involved are indicated by the following ignition temperatures: $315,385,530,640 \mathrm{C}$, corresponding to the following specific areas: 50 , $4.7,1.6,0.28 \mathrm{~cm}^{2} / \mathrm{gm}$, respectively. Uranium powder, of about twomicron size, gave an oxygen ignition temperature of $125 \mathrm{C}$, which is substantially ( $110 \mathrm{C}$ ) below the prediction based on the above relation. Uncertainty in estimating the effective specific area of the powder particles was held responsible for this discrepancy. This powder ignition temperature agrees well, however, with data of Hartmann ${ }^{(7)}$ for $U$ powder layers involving particles of comparable size. It will be recalled that Hartmann achieved room temperature ignition of uranium powder dispersed in cloud form. The sensitivity of the ignition phenomenon to specific area, nature of the particle dispersion, as well as the activation agenoy; has been clearly manifested in these studies cited above. The difficulty of applying a relation such as given above to a working environment--where there is substantial ignorance concerning the potential range of $A_{p}^{*}$, the nature of the active aggregates, and the activation agencies--is clearly obvious.

The ANL study has shown that there is a marked variation in ignition behavior of uranium specimens from various sources and a strong sensitivity to the metallurgical history of specimens from a given source. With respect to beta quenched uranium, as-cast uranium exhibited significantly higher isothermal oxidation rates and lower ignition temperatures at comparable specific areas. Uranium specimens from different sources, with apparently trivial differences in composition, exhibited an ignition temperature difference of the order of $350 \mathrm{C}$ under identical test conditions. The activating factors responsible for these source and metallurgical history influences were not identified.

Various elements, Mo, $\mathrm{Cu}, \mathrm{Ru}, \mathrm{Fe}, \mathrm{Zr}, \mathrm{Nb}, \mathrm{Be}, \mathrm{Al}$, Si, and $\mathrm{C}$, were added separately to $U$ (up to about $3 \mathrm{a} / \mathrm{o}$ ) and the ignition and isothermal oxidation characteristics of the dilute binary alloys studied. Isothermal oxidation tests at $200 \mathrm{C}\left(200 \mathrm{~mm} \mathrm{O}_{2}\right)$ showed that none of the above additives increased the oxidation rate of $U$ significantly. Burning curve tests, however, showed that $\mathrm{Al}$, in about $1 \mathrm{a} / 0$ concentration, decreased the $\mathrm{T}_{\text {ig }}$ by about $200 \mathrm{C}$. Copper, in the same concentration, raised the $\mathrm{T}_{\text {ig }}$ by roughly the 
same amount. These effects were sensitive to the specific area of the specimens. When foils with an $A_{p}^{*}$ of about $5 \mathrm{~cm}^{2} / \mathrm{gm}$ were used, these additions had no effect on the $\mathrm{T}_{\mathrm{ig}}$. As noted in Section IV, recent ORNL data tend to corroborate this influence of $\mathrm{Al}$ on the ignition temperature of massive $U$. Low temperature $(200 \mathrm{C})$ isothermal oxidation tests of the $\mathrm{U}-\mathrm{Al}$ system at ANL have failed to provide a clue in explanation of this Al action.

Conditions, such as a rough surface or macro cracks, which increase the surface area associated with a given mass of metal would be expected to influence the ignition characteristics. The ANL study showed that the velocity of propogation of an ignition front on foil specimens was increased ( $\sim 30$ per cent) by roughening the surface with an $\mathrm{HNO}_{3}$ etch. Burning curve, or shielded ignition tests were apparently not performed with massive $U$ specimens containing an extensive crack system, or with an abnormally high effective surface area. Such tests would be of considerable value in appraising the effect of irradiation damage on the pyrophoricity of U. Quantitative physical characterization, and duplication, of such specimens would pose some difficulty. It is becoming increasingly obvious, however, that the potential of simple, single particle, tests for providing information useful to hazards analyses may be approaching exhaustion. For example, work at ANL has shown that a small quantity of powder, intersperced with massive $U$ pieces, can profoundly affect the ignition characteristics of the system. If a significant extension of present knowledge on pyrophoricity is to be gained, the complex nature of the physical and chemical exchanges involved in ignition of a "working" metal system will require somewhat more reliance on experimental analysis of such systems.

\section{B. Influence of Environmental Factors}

The bulk of the ANL oxidation and ignition work has been performed under a pure oxygen atmosphere. Ignition in oxygen is characterized by a brilliant white flash, followed by rapid consumption of the specimen. When air is substituted for oxygen, two marked changes in ignition behavior are 

requirements. It is of some interest that $\mathrm{ANL}$ workers found $\mathrm{CO}_{2}$ to be an efficient quench for ignition which had been started in air, or pure oxygen. Carbon dioxide was reportedly as effective as helium in this respect, once the $\mathrm{O}_{2}$, or air, had been removed.

The ANL program recently has also included study of molten metal-water/steam reactions. As noted above, reactions between reactor metals and water, or steam, are potentially prime contributors to the chemical energy release consequent from loss of temperature control in a reactor. This aspect of the hazard associated with reactor core metals, and the derivative hazard of hydrogen-air explosions, will be discussed in a subsequent report.

VII. CONCLUSION

An attempt has been made in the previous discussion to identify the more important factors influencing the character of a pyrophoric event. A brief review of these factors, and a summary of the status of the specific problem presented by uranium fuel element fires, follow.

Factors affecting pyrophoricity:

a. The inherent reactivity of the active substance and the heat release per volume of reacting material.

b. The specific area $\left(A_{p}^{* k}\right)$ of the reacting particles.

c. The physical and chemical coupling among reacting particles.

d. The rate of exposure of active material.

e. Subsidiary heat producing reactions, such as the combustion of hydrogen.

f. The cooling and oxidizing potentials of the environment.

Factors related to uranium:

a. The $U$-air reaction satisfies the ignition requirements for reactivity and heat release over a wide range of environmental conditions. Under certain conditions, $U$ ignition can be sustained in $\mathrm{N}_{2}$, or $\mathrm{CO}_{2}$ atmospheres. Uranium reactions with water and steam are important in two respects: in water cooled reactors these reactions 
determine the extent of the protective oxidation prior to air exposure; the hydrogen generated by these reactions can augment the hazard potential either as free $\mathrm{H}_{2}$, or in the compound $\mathrm{UH}_{3}$. The $\mathrm{UH}_{3}$ is believed to be an important participant in fuel element fires. This compound is dangerous as a consequence of its inherent reactivity and its tendency to generate powdered forms of either $\mathrm{UH}_{3}$ or uranium.

b. The effect of irradiation on the pyrophoricity of uranium remains obscure. The evidence presented in this review does not indicate a strong irradiation influence. It is submitted that the two main effects of irradiation with respect to fuel element fires are: increase in the potential active surface associated with a given mass of $U$ through the development of cracks, and porosity; self heating from radioactive decay. The pyrophoric activation derived from fission and decay products may be significant under certain conditions-specifically: high irradiation exposures and high fuel element temperatures; rapid exposure of the core to air immediately following, or in the course of, irradiation.

c. Aluminum, in small concentrations, has shown an ability to significantly lower the ignition temperature of massive uranium.

d. Helium has been found effective in inhibiting and quenching uranium and $\mathrm{UH}_{3}$ ignition. Carbon dioxide is a potent suppressant of hydrogen explosions and, in addition, has exhibited some potential for quenching uranium fires. The reactivity of $\mathrm{CO}_{2}$ and $\mathrm{UH}_{3}$ at low temperatures may disqualify $\mathrm{CO}_{2}$ as a quench for fuel element fires, although further information in this respect is needed.

Specific problems related to Hanford fuel elements:

a. Early detection of cladding defects.

b. Minimizing the time between defect detection and removal from the reactor.

c. Development of discharge techniques with a small potential for contributing to destruction of the fuel element.

d. Development of a practicable quench gas, or inert foam blanket, for regular, or standby, use during discharge operations 
e. Installation of permanent, or temporary, structural modifications to the discharge area which virtually preclude hold-up of a free fuel element--either in the rear face hardware, or on the building.

f. Development of equipment capable of rapid recovery of held-up fuel elements--which are a finite possibility despite the most elaborate precautions. When the individual handling of fuel elements is practicable, use of isolation capsules for defected elements may be warranted under certain conditions.

The use of a fog spray system in the rear face area is probably justified on the basis of its potential for fission product containment and rear face decontamination. The influence of the spray on a fuel element fire would depend on the condition of the element and the characteristics of the spray in the region of the element. It is not improbable that there are certain combinations of fuel element and spray conditions which might aggravate the fire situation. Both the cooling and air dilution possibilities attending use of the spray system tend to counter this adverse effect. Application of the fog spray would result in some loss of visual contact with the trouble zone. Unless efficient slug recovery and fire control facilities-requiring direction to the fuel element--were available, loss of visual contact would probably not add to the difficulties.

Experimental objectives relating to prevention and control of fuel element fires:

a. Tests with various aggregates of $U$ and $\mathrm{UH}_{3}$, with and without contact with massive $\mathrm{U}$, to determine the potential of $\mathrm{He}$ and $\mathrm{CO}_{2}$, used separately and in combination, for quenching and inhibiting ignition. The violence of these test fires could be made comparable to any conceivable fire condition presented by a fuel element. The use of steam, as a first stage quench and coolant agent, should be explored by virtue of its potential for rapid development of protective oxides. Steam treatment of large masses of molten metal would be preferable to water treatment because of the possible 
steam explosion effects--including metal dispersion--attending the application of water to a high temperature system.

b. Ex-reactor melt-down tests, under atmospheres of potential importance, using fuel elements and process tube sections. Melt-down tests should be made with fuel elements separately, and under normal conditions of contact with the process tube. Duplication of the temperature histories which could obtain under reactor accident conditions would probably not be feasible. Relatively simple, essentially isothermal, melt-down tests would, however, advance the present limited knowledge of the complex physical and chemical processes affecting the fire consequences of a melt-down incident.

The fission product release potential of a single fuel element fire is more than ample justification for prompt attention to these matters. A somewhat better perspective is gained by considering the pivotal role of the fuel elements in the chain of consequences resulting from a reactor accident. The course of the accident is, to a large extent, determined by the physical, chemical, and nuclear response of the fuel element-process tube system to the accident conditions. The practical problem of paramount interest lies in determining the extent to which this response can be favorably influenced by emergency procedures and design of core components.

\section{ACKNOWLEDGEMENT}

The preparation of a substantial fraction of this report has been made possible through the cooperation of a large number of Hanford staff members in the laboratory and reactor operation groups. The assistance of the library staff is gratefully acknowledged. 


\section{BIBLIOGRAPHY}

1. Smith, R. B. The Fire Properties of Metallic Uranium, TID-8011. April 12, 1956

2. Smith, R.B. "Pyrophoricity-- A Technical Mystery Under Vigorous Attack, "Nucleonics. December, 1956.

3. Smith, R. B. AEC Uranium Fire Experience, HAN-56765.

September 17, 1954. (SECRET).

4. Conway, J. B. and A. V. Grosse. Powdered Metal Flames, NP-4 962. August 1, 1953.

5. Katz, J. and G. T. Seaborg. The Chemistry of the Actinide Elements. New York: Wiley \& Sons, 1957.

6. Doyle, W. L。, et al. Inorganic Nuclear Chemistry, Vol. 16: 138. 1958.

7. Hartmann, I. The Explosivity of Ti, Zr, Th, U, and Their Hydrides, NYO-1562. June 20, 1951.

8. Kennard, E. H. Kinetic Theory of Gases. New York: McGraw-Hill, 1938.

9. Coward, H.F. and G. W. Jones. Limits of Flammability of Gases and Vapors, Bulletin 503. Bureau of Mines, 1952.

10. Warf, J. C. Chemical Properties of $\mathrm{UH}_{3}$, AECD-2997. September 29, 1949 .

11. Long, G., et al. Explosions of Aluminum and Water, Report No. 2-50-33. Aluminum Company of America. August, 1950.

12. Higgins, H. M. and R. D. Schultz. The Reactions of Metals with Water and Oxidizing Gases at High Temperatures, IDO-28000. April 30, 1957.

13. Waber, J. T. A Review of the Corrosion Behavior of Uranium, LA-2035. December 29, 1958.

14. Waber, J. T. The Corrosion Behavior of Plutonium and Uranium, Geneva Paper No. 699.

15. Healy, J. G. Single Tube Failures, HW-31127. March 12, 1954 . (SECRET).

16. Holden, A。N. Physical Metallurgy of Uranium. Reading, Mass.: Addison-Wesley Publishing Company, 1958.

17. Atwood, J. M., et al. Recirculation Loop Rupture Incident at 100-H, HW-40115. November 22, 1955 .

18. Selby, J.M. and J. K. Soldat. Summary Report of Environmental Contamination Incidents at Hanford, HW-54636. January 25, 1958. (CONFIDENTIAL). 
19. Leitz, E: E: Burning of Enriched U, I \& E Slug at C Reactor: Unpublished Report. (CONFIDENTIAL)

20. Meyers, J. G. Irradiation Processing Department Radiation Occurrence Investigation Report, $\mathrm{HW}-60274$. May 5, 1959. (CONFIDEINTIAL).

21. Kittel, J. H. Spontaneous Ignition of Highly Irradiated Fuel, TID-2508. December, 1955. (CONFIDENTIAL)

22. Linderoth, C., Hanford Laboratory. Private Communication.

23. Hurst, D. G. The Accident of the NRX Reactor, Part II, GPI-14. October 23, 1953.

24. British White Paper on Windscale Accident, October 10, 1957.

25. O'Keefe, D. P. and J. E. Minor. Final Report of K Reactor Incident, HW-35822. August 25, 1955. (SECRET).

26. Loftness, R. L. A Vapor Pressure Chart for Metals, NAA-SR-132. July 10, 1952 .

27. Uranium Data Manual, IGR-R-R-287. 1958

28. Brugman, E. W. and R. B. Hoxeng. "The Corrosion of Uranium," N.N.E.S., Vol: IV-6A. 1951. (CONFIDENTIAL).

29. Zima, G. E. A Review of the Properties of Zircaloy-2, HW-60908. October, 14, 1959.

30. Gens, T. A. Explosive Reactions During Reprocessing of Reactor Fuels Containing U and Zr or Nb, ORNL-CF-58-11-31. November 13, 1958.

31. Mash, D. R. and B. F. Disselhorst. Uranium-Zirconium Diffusion Studies, AECD-3701. 1954.

32. Rough, F. A. and A. A. Bauer. Constitutional Diagrams of Uranium and Thorium Alloys. Reading, Mass.: Addison-Wesley, 1958.

33. Katz, J. J. and E. Rabinowitch. "The Chemistry of Uranium," N.N.E.S. , Vol: VIII-5.

34. Lustman, B. and F. Kerze. The Metallurgy of Zirconium. New York: McGraw-Hill, 1955.

35. Barnartt, S., et al. "Oxidation of $50 \mathrm{w} / \mathrm{o} \mathrm{U}-\mathrm{Zr}$ Alloy, " J. ElectroChem. Soc., p. 218. April, 1957.

36. Huddle, R. A. The Uranium-Steam Reaction, AERE-M-R-1281. November, 1953.

37. Wathen, T. Corrosion of U Metal in Air and Steam at Various Temperatures, BR-223A. May 13, 1943.

38. Hopkinson, B. E. "Kinetics of the U-Steam Reaction," J. ElectroChem. Soc., p. 102. February, 1959.

39. Lemmon, A. W. The Reaction of Steam with U and with Various U-Nb and $\mathrm{Zr}$ Alloys at High Temperatures, BMI-1192. January 17, 1957. 
40. Scott, A. J., Hanford Laboratory. Private Communication.

41. Antill, J. E., et al. Kinetics of the Oxidation of $\mathrm{U}$ by $\mathrm{CO}_{2}$, AERE-M-R-2524. 1958.

42. Albrecht, W. M. and M. W. Mallett. "Reaction of Hydrogen with Uranium, " J. Electro-Chem. Soc., p.404. July, 1956.

43. Albrecht, W. M. and M. W. Mallett. "Reaction of Hydrogen with Uranium," J. Electro-Chem. Soc., p. 610. October, 1958.

44. Mallett, M. W. and M. J. Trzeciak. "Hydrogen-Uranium Relationships, "Trans. ASM, p. 981. 1958.

45. Gibb, T. R., et al. "The U-H System," J. Am. Chem. Soc. 74, 6203. 1952 .

46. Smith, E. A. On the Mechanism of In-Pile Slug Ruptures, HW-25877. October 23, 1952. (SECRET).

47. Smith, M. L. A Summary of the Pyrophoricity Hazards of Ruptured Fuel Elements, HW-48013. January 28, 1957. (SECRE'T).

48. Schnizlein, J. H. , et al. Ignition Behavior and Kinetics of Oxidation of the Reactor Metals, Uranium, Zirconium, Plutonium, Thorium, and Binary Alloys of Each, ANL-5974. April, 1959.

49. Hilliard, R. K. Oxidation of $U$ in Air at High Temperatures, HW-58022. December 10, 1958. 


\section{INTERNAL DISTRIBUTION}

\section{Copy Number}

O. E. Adams

E. R. Astley

J. A. Ayres

J. M. Batch

J. H. Brown

A. C. Callen

P. A. Carlson

A. B. Carson

D. H. Curtiss

R. L. Dickeman

E. L. Etheridge

T. W. Evans

P. C. Jerman

R. T. Jessen

J. M. Fox

W. D. Gilbert

O. H. Greager

A. R. Hardin

H. W. Heacock

J. W. Healy

R. K. Hilliard

S. S. Jones

C. G. Lewis

N. R. Miller

J. E. Minor

M. R. Moon

R. Nilson

K. W. Norwood

R. W. Reid

G. J. Rogers

A. J. Scott

E. A. Smith

M. L. Smith

H. G. Spencer

J. C. Tobin

R. E. Trumble

F. W. VanWormer

N. G. Wittenbrock

300 Files

Record Center

Extra

G. E. Technical Data Center, Schenectady 


\section{EXTERNAL DISTRIBUTION}

\section{No. of Copies}

\begin{tabular}{|c|c|}
\hline 2 & Aberdeen Proving Ground \\
\hline 1 & Aerojet-General Corporation \\
\hline 1 & Aerojet-General, San Ramon (IOO-880) \\
\hline 1 & AFPR, Boeing, Seattle \\
\hline 1 & AFPR, Lockheed, Marietta \\
\hline 2 & ANP Project Office, Convair, Fort Worth \\
\hline 1 & Alco Products, Inc. \\
\hline 1 & Allis-Chalmers Manufacturing Company \\
\hline 10 & Argonne National Laboratory \\
\hline 1 & Army Ballistic Missile Agency \\
\hline 1 & AEC Scientific Representative, Belgium \\
\hline 1 & AEC Scientific Representative, Japan \\
\hline 3 & Atomic Energy Commission, Washington \\
\hline 1 & Atomic Energy Commission, Washington \\
\hline 3 & $\begin{array}{l}\text { Attn: J. William Young, Industrial Information, TIS } \\
\text { Atomics International }\end{array}$ \\
\hline 4 & Babcock and Wilcox Company (NYOO-1940) \\
\hline 2 & Battelle Memorial Institute \\
\hline 4 & Bettis Plant \\
\hline 2 & Brookhaven National Laboratory \\
\hline 1 & Brush Beryllium Company \\
\hline 1 & Bureau of Mines, Albany \\
\hline 1 & Bureau of Ships (Code 1500) \\
\hline 3 & Chicago Operations Office \\
\hline 1 & Chicago Patent Group \\
\hline 2 & Combustion Engineering, Inc. \\
\hline 1 & Convair-General Dynamics Corporation, San Diego \\
\hline 1 & Defence Research Member \\
\hline 1 & Denver Research Institute \\
\hline 2 & Department of the Army, G-2 \\
\hline 1 & Dow Chemical Company (Rocky Flats) \\
\hline 4 & duPont Company, Aiken \\
\hline 1 & duPont Company, Wilmington \\
\hline 1 & Frankford Arsenal \\
\hline 1 & General Atomic Division \\
\hline 2 & General Electric Company (ANPD) \\
\hline 1 & General Electric Company, St. Petersburg \\
\hline 1 & General Nuclear Engineering Corporation \\
\hline 1 & Goodyear Atomic Corporation \\
\hline 1 & Grand Junction Operations Office \\
\hline 2 & Iowa State College \\
\hline 2 & Jet Propulsion Laboratory \\
\hline 3 & Knolls Atomic Power Laboratory \\
\hline 3 & Los Alamos Scientific Laboratory \\
\hline 1 & M \& C Nuclear, Inc. \\
\hline 2 & Mallinckrodt Chemical Works \\
\hline 1 & Maritime Administration \\
\hline
\end{tabular}


EXTERNAL DISTRIBUTION (contd。)

No. of Copies

Martin Company

Mound Laboratory

National Aeronautics and Space Administration, Cleveland

National Bureau of Standards

National Bureau of Standards (Library)

National Lead Company of Ohio

Naval Research Laboratory

New Brunswick Area Office

New York Operations Office

Nuclear Development Corporation of America

Nuclear Metals, Inc.

Oak Ridge Institute of Nuclear Studies

Office of Naval Research

Office of Naval Research (Code 422)

Office of Ordnance Research

Olin Mathieson Chemical Corporation

Ordnance Materials Research Office

Ordnance Tank-Automotive Command

Patent Branch, Washington

Phillips Petroleum Company (NRTS)

Picatinny Arsenal

Power Reactor Development Company

Pratt and Whitney Aircraft Division

Rensselaer Polytechnic Institute

Sandia Corporation, Albuquerque

Stevens Institute of Technology (Comstock)

Sylvania Electric Products, Inc.

Technical Research Group

Tennessee Valley Authority

Union Carbide Nuclear Company (ORGDP)

Union Carbide Nuclear Company (ORNL)

Union Carbide Nuclear Company (Paducah Plant)

USAF Project RAND

U. S. Geological Survey, Denver

U. S. Geological Survey, Menlo Park

U.S. Geological Survey, Washington

U.S. Naval Postgraduate School

U.S. Patent Office

University of California, Berkeley

University of California, Livermore

University of Puerto Rico

Watertown Arsenal

Westinghouse Electric Corporation (Schafer)

Wright Air Development Center

Yankee Atomic Electric Company

Technical Information Service Extension

Office of Technical Services, Washington 
UNCLASSIFIED 